\title{
Outbreak Response and Incident Management: SHEA Guidance and Resources for Healthcare Epidemiologists in United States Acute-Care Hospitals
}

\author{
David B. Banach, MD, MPH, MS; ; ${ }^{1, a}$ B. Lynn Johnston, MD, MS, FRCPC; ;,a Duha Al-Zubeidi, MD; ${ }^{3}$ Allison H. Bartlett, MD, MS; ${ }^{4}$ \\ Susan Casey Bleasdale, MD; ${ }^{5}$ Valerie M. Deloney, MBA; ${ }^{6}$ Kyle B. Enfield, MD, MS; ${ }^{7}$ Judith A. Guzman-Cottrill, DO; \\ Christopher Lowe, MD, MSc; ${ }^{9}$ Luis Ostrosky-Zeichner, MD; ${ }^{10}$ Kyle J. Popovich, MD, MS; ${ }^{11}$ \\ Payal K. Patel, MD; ${ }^{12}$ Karen Ravin, MD, MS; ${ }^{13}$ Theresa Rowe, DO, MS; ${ }^{14}$ Erica S. Shenoy, MD, PhD; ${ }^{15}$
} Roger Stienecker, MD; ${ }^{16}$ Pritish K. Tosh, MD; ${ }^{17}$ Kavita K. Trivedi, MD; ${ }^{18}$ and the Outbreak Response Training Program (ORTP) Advisory Panel ${ }^{\mathrm{b}}$

\section{PURPOSE}

This expert guidance document was developed as a resource to provide healthcare epidemiologists working in acute-care hospitals with a high-level overview of incident management for infectious diseases outbreaks and to prepare them to work within an emergency response framework. It addresses how the epidemiologist's skills and expertise apply to scenarios that require enhanced preparedness and response efforts, eg, when pathogens associated with outbreaks are poorly characterized or when outbreaks require additional interventions including, but not limited to, healthcare personnel education, enhanced infection prevention and control measures, added staffing, supplies, and resources, adjustments to clinical and support activities, and external communications. Its recommendations are not pathogen-specific and are meant to apply to a range of potential infectious diseases outbreaks. To provide high-level guidance and context for incident management, the authors specify recommendations for the healthcare epidemiologist, as well as involvement and responsibilities of the facility and other healthcare personnel (HCP).

\section{A UTHORS}

In May 2016, SHEA members submitted online applications for the Society for Healthcare Epidemiology of America (SHEA)/Centers for Disease Control and Prevention (CDC) Outbreak Response Training Program (ORTP) panels, which were responsible for the content development for the multifaceted educational, training, and guidance opportunities provided by the ORTP: Advisory Panel, Expert Guidance Panel, and Education Panel. Panel members were selected based on their expertise in outbreak response, professional background, and involvement with SHEA and other organizations working in outbreak response and relevant fields. Each panel was composed of multidisciplinary experts in public health, emergency medicine, hospital medicine, community medicine, microbiology, pediatrics, and long-term care, with additional expertise in infectious diseases including Ebola virus disease (EVD), pandemic influenza, carbapenem-resistant Enterobacteriaceae (CRE), multidrug-resistant tuberculosis (MDR-TB), Middle East respiratory syndrome-coronavirus (MERS-CoV), severe acute respiratory syndrome (SARS), and Zika virus.

Affiliations: 1. University of Connecticut School of Medicine, Farmington, Connecticut; 2. Dalhousie University, Halifax, NS, Canada; 3. Children's Mercy Kansas City, Kansas City, Missouri; 4. University of Chicago Medicine, Comer Children's Hospital, Chicago, Illinois; 5. University of Illinois, Chicago, Illinois; 6. Society for Healthcare Epidemiology of America, Arlington, Virginia; 7. University of Virginia, Charlottesville, Virginia; 8. Oregon Health and Science University Hospital, Portland, Oregon; 9. Providence Health Care, Vancouver, British Columbia, Canada; 10. McGovern Medical School, Houston, Texas; 11. Rush University Medical Center, Chicago, Illinois; 12. Veterans Affairs Ann Arbor Healthcare System, Ann Arbor, Michigan; 13. Nemours/Alfred I DuPont Hospital for Children, Wilmington, Delaware; 14. Northwestern University Feinberg School of Medicine, Chicago, Illinois; 15. Massachusetts General Hospital and Harvard Medical School, Boston, Massachusetts; 16. Parkview Health System, Fort Wayne, Indiana; 17. Mayo Clinic, Rochester, Minnesota; 18. Trivedi Consults, LLC, Berkeley, California.

${ }^{\mathrm{a}}$ Co-chairs.

${ }^{b}$ Members of the Outbreak Response Training Program (ORTP) Advisory Panel (in alphabetical order): Muhammad S. Ashraf, MBBS, Omaha, NE; E. Yoko Furuya, MD, MS, New York, NY; Judith A. Guzman-Cottrill, DO (Chair of ORTP Advisory Panel), Portland, OR; Susy Hota, MD, MSc, Toronto, Ontario, Canada; Nicole Iovine, MD, Gainesville, FL; Jesse T. Jacob, MD, MSc, Atlanta, GA; Amy B. Kressel, MD, MS, Indianapolis, IN; Larissa May, MD, MSPH, MSHS, Sacramento, CA; Rekha Murthy, MD, Los Angeles, CA; Ann-Christine Nyquist, MD, Aurora, CO; Belinda Ostrowsky, MD, MPH, Bronx, NY; Nasia Safdar, MD, PhD, Madison, WI; and Heather Young, PhD, MPHDenver, CO.

Received September 2, 2017; accepted September 14, 2017

(C) 2017 by The Society for Healthcare Epidemiology of America. All rights reserved. 0899-823X/2017/3812-0002. DOI: 10.1017/ice.2017.212 
The SHEA/CDC ORTP Expert Guidance Writing Panel (ie, the authors) were selected based on additional expertise in guidance and guideline-writing, and are the primary authors of this document. Advisory Panel members, the overseeing body for the entire ORTP, contributed to this guidance by conducting a needs assessment to determine knowledge gaps and identify effective strategies for outbreak response and incident management, and by reviewing, analyzing, and summarizing resources identified by the CDC for the Expert Guidance Panel to consider for inclusion in the expert guidance document, and by reviewing and providing comments on drafts and the final version of the expert guidance document (see the Methods section).

\section{B A C K G R O U N D}

The 6 major factors identified by the Institute of Medicine (IOM) in 1992 as contributing to infectious disease emergence and reemergence-advances in technology, increases in volume and speed of international travel and commerce, microbial adaptation and change, and the breakdown of public health capacity at the local, state, national, and global levelshave intensified over time. ${ }^{1}$ Emerging pathogen outbreaks in the United States and abroad can occur with little forewarning, disrupting hospital operations, limiting capacity to provide services to patients, and possibly compromising the safety of healthcare personnel (HCP). This expert guidance document (EG) was developed as a resource to provide healthcare epidemiologists (HEs) with a high-level overview of incident management for infectious diseases outbreaks, and includes references to help with operationalizing its recommendations.

While outbreak management is a major area of responsibility for HEs, ${ }^{2}$ many do not have formal education in incident management or preparation to work within an emergency response framework. This document addresses how HE skills and expertise apply to scenarios that require enhanced preparedness and response efforts, eg, when pathogens associated with outbreaks are characterized poorly (source, means of transmission, and/or disease outcome) or when outbreaks require additional interventions including, but not limited to, healthcare personnel (HCP) education; enhanced infection prevention and control measures; added staffing, supplies, and resources; adjustments to clinical and support activities; and external communications.

\section{INTENDED USE}

This document is intended for US HEs working in acute-care hospitals. Its principles may be applicable to other types of facilities, eg, free-standing emergency departments, urgent care centers, long-term care, and nontraditional acute-care settings; however, the primary goal of this document is to provide guidance and resources focused on the acute-care hospital setting. Its recommendations are not pathogenspecific and are meant to apply to a range of potential infectious diseases outbreaks.
To provide high-level guidance and context for incident management, the authors specify recommendations for the $\mathrm{HE}$, as well as involvement and responsibilities of the facility and other HCP. In this guidance document, the term "facility," when used in the recommendations, refers to facility leaders' assignments of responsibilities to appropriate individuals or groups. Roles that these individuals take may vary depending on the facility.

SHEA develops special topic EGs for areas that lack the level of evidence required for a formal guideline developed using the Grading of Recommendations Assessment, Development and Evaluation (GRADE) or a similar systematic methodology; they are important in provision of safe, effective health care. Expert guidance documents are based on synthesis of available evidence, theoretical rationale, current practices, practical considerations, writing group opinion, and consideration of potential harm where applicable. As such, evidence level is not provided for individual recommendations. ${ }^{3}$ Although regulations are referenced throughout the document, this guidance document should not be used in a regulatory capacity.

No EG can anticipate all situations and this guidance document is not meant to be a substitute for individual judgment by qualified professionals.

\section{METHODS}

\section{Needs Assessment}

The Advisory Panel conducted a needs assessment to determine knowledge gaps and identify effective strategies for outbreak response and incident management. The assessment survey was sent to US SHEA Research Network Members (SRN) via an online survey (Appendix 1: Needs Assessment for Results and Discussion), and the results were used to prioritize topics for the EG.

\section{Document Development}

The authors followed the process outlined in the "Handbook for SHEA-Sponsored Guidelines and Expert Guidance Documents." ${ }^{3}$ The writing panel wrote PICO-style (ie, population, intervention, control, and outcome) questions to set the scope of the document. These questions were used in the development of search terms, and both the questions and search terms were voted on by the writing panel until unanimous approval was achieved (see the online supplemental Literature Review Table).

Resources for this document were drawn from 2 separate review processes. The CDC provided a list of resources that included government resources, hospital policies and guidance, standards and regulations, and articles published in peer-reviewed literature. Advisory Panel members reviewed each resource from the perspective of the HE to identify terminology, frameworks, partners/stakeholders, and skill development opportunities, as well as to evaluate its relevance 
for use in facility and/or emerging pathogen outbreaks and provided the reviews to the authors to consider for inclusion in the expert guidance document (EG). When deemed appropriate by the authors, additional resources evaluated for relevance and quality were added (see the online supplemental Literature Review Table).

The authors conducted a separate review of literature published from January 1, 1990, to October 1, 2016. Only English language articles with abstracts were included in the review. A primary reviewer and secondary reviewer assessed the articles generated from the searches for potential inclusion in the document (see the online supplemental Literature Review Table).

The EG synthesizes the CDC-provided resources and literature review findings to provide practical guidance and useful references to the $\mathrm{HE}$ for incident management of infectious diseases outbreaks. SHEA expert guidance documents apply a formalized process for obtaining expert consensus. Recommendations are listed with rationale statements that consider relevant evidence as well as the consensus of the group. Consensus is determined via an anonymous voting and comment period. ${ }^{3}$

\section{Review, Clearance, and Endorsement}

The following organizations provided reviews and comments: American Association of Critical-Care Nurses (AACN), American College of Emergency Physicians (ACEP), the Association for Professionals in Infection Control and Epidemiology (APIC), the CDC, the SHEA Guidelines Committee, the SHEA Publications Committee, and the SHEA Board of Trustees.

The EG was approved for publication by the ORTP Advisory Panel, the SHEA Guidelines Committee, the SHEA Publications Committee, and the SHEA Board of Trustees. It also received CDC clearance.

The following organizations endorse the guidance: SHEA, the American Association of Critical-Care Nurses (AACN), the American College of Emergency Physicians (ACEP), the Council of State and Territorial Epidemiologists (CSTE), HCA Healthcare, the Infectious Diseases Society of America (IDSA), The Joint Commission, the National Association of County and City Health Officials (NACCHO), and the Pediatric Infectious Diseases Society (PIDS).

\section{GUIDANCE STATEMENT}

\section{Incident Management}

The term "incident management" describes the activities an organization takes to prepare for, respond to, and learn from an event or hazard, including service interruptions (eg, telecommunication), local events (eg, municipal flood or fire), and larger events (eg, mass casualty or international epidemic). This section provides an overview of incident management for infectious diseases outbreaks and the federal, state/territorial/ regional, and facility-based structures that drive those activities. While the HE does not have responsibility for many of the actions recommended in this section, they provide the HE with relevant context and background into facility incident management.

This section's recommendations reference incident management terminology that may be unfamiliar to the reader (Table 1). They are explained further in the rationale sections where they appear.

\section{Incident Management Organizational Structures}

\section{Recommendations.}

1. A facility should use an Emergency Management Program (EMP) to identify its goals and vision related to emergency management and to guide it through the incident management phases of preparedness, mitigation, response, and recovery from a crisis.

2. The facility should use an all-hazards self-assessment to inform the EMP and determine how it can fulfill its core mission of patient care during incidents, including infectious diseases outbreaks.

3. Within the EMP, the facility should create an emergency operations plan (EOP) that includes 6 critical components, as required by The Joint Commission's Emergency Management Standards:
a. Communications
b. Resources and assets
c. Safety and security
d. Staff responsibilities
e. Utilities
f. Clinical support activities

4. The facility should assess the adequacy of the EOP by conducting drills, competency assessments, and simulation exercises.

5. The facility should coordinate and communicate outbreak response through the Hospital Incident Command System (HICS).

Rationale. Figure 1 illustrates how the following federal to facility-level incident management structures are organized.

The National Incident Management System (NIMS), overseen by the Federal Emergency Management Agency (FEMA), provides a common standard for collaboration between federal, state, tribal and local governments, and nongovernmental organizations during crises. The NIMS facilitates communication, ${ }^{4,5}$ provides a uniform approach to procedures, protocols, and expectations, ${ }^{6,7}$ and guides integration of diverse entities that, if necessary, can establish unified command by combining incident command structures. ${ }^{5}$ The NIMS components for incident management have been summarized as follows ${ }^{4,5}$ :

1. Preparedness

2. Communications and information management 
TABLE 1. Terminology

\begin{tabular}{|c|c|}
\hline $\operatorname{Term}(s)$ & $\begin{array}{l}\operatorname{Acronym}(\mathrm{s}) \text { and } \\
\text { Similar Term }(\mathrm{s})\end{array}$ \\
\hline All-hazards preparedness & Needs assessment \\
\hline CDC Crisis and Emergency Risk Communication & CERC \\
\hline Centers for Disease Control and Prevention & $\mathrm{CDC}$ \\
\hline Centers for Medicare and Medicaid Services & CMS \\
\hline $\begin{array}{l}\text { Common operating procedure, } \\
\text { common operating picture }\end{array}$ & COP \\
\hline Department of Health & $\mathrm{DOH}$ \\
\hline Department of Health and Human Services & HHS \\
\hline Ebola virus disease & EVD \\
\hline Emergency department & $\mathrm{ED}$ \\
\hline Emergency management program & EMP \\
\hline Emergency Medical Services & EMS \\
\hline Emergency operations plan & EOP \\
\hline Emergency support function & ESF \\
\hline Expert guidance document (SHEA) & EG \\
\hline Federal Emergency Management Agency & FEMA \\
\hline Hazard vulnerability analysis, risk assessment & HVA \\
\hline Healthcare personnel & $\mathrm{HCP}$ \\
\hline Healthcare epidemiologist & $\mathrm{HE}$ \\
\hline Hospital incident command system & HICS \\
\hline Hospital incident management team & HIMT \\
\hline $\begin{array}{l}\text { Hospital command center } \\
\text { Healthcare coalition }\end{array}$ & $\mathrm{HCC}$ \\
\hline Hospital preparedness program & HPP \\
\hline Incident command system & ICS \\
\hline Unified command & $\mathrm{UC}$ \\
\hline Incident commander & IC \\
\hline Infectious disease & ID \\
\hline Infection preventionist & IP \\
\hline Job action sheet & JAS \\
\hline Laboratory response network & LRN \\
\hline Liaison officer & LO \\
\hline Long-term care facility & LTCF \\
\hline Medical screening examination & MSE \\
\hline Middle East respiratory syndrome coronavirus & MERS-CoV \\
\hline Multidrug-resistant organism & MDRO \\
\hline National Disaster Medical System & NDMS \\
\hline National Incident Management System & NIMS \\
\hline National response framework & $\mathrm{NRF}$ \\
\hline $\begin{array}{l}\text { Office of the Assistant Secretary for Preparedness } \\
\text { and Response }\end{array}$ & ASPR \\
\hline $\begin{array}{l}\text { Office of Public Health Preparedness and } \\
\text { Response, CDC }\end{array}$ & PHPR \\
\hline Person under investigation & PUI \\
\hline Personal air purifying respirators & PAPR \\
\hline Personal protective equipment & PPE \\
\hline Public information officer & $\mathrm{PIO}$ \\
\hline Reusable medical equipment & RME \\
\hline Safety officer & SO \\
\hline Severe acute respiratory syndrome & SARS \\
\hline
\end{tabular}

3. Resource management

4. Command and management

5. Ongoing management and maintenance
The NIMS provides the template for incident management, and the US National Response Framework (NRF) describes the structures by which the federal government responds to crises. Together, NIMS and NRF integrate incident management capabilities from the federal to local level. The NRF is comprised of 20 emergency support functions (ESFs), which create a structure for federal interagency response to states. ${ }^{8}$ From the federal to facility levels, a common operating picture (COP) ensures consistency in incident information, decision making, and status updates.

The federal government supports state and local authorities when resources are limited or overwhelmed. The Assistant Secretary for Preparedness and Response (ASPR)'s Hospital Preparedness Program (HPP) focuses on preparedness strategies for situations when healthcare capacity is stretched. Under the HPP are Health Care Coalitions (HCCs), which are comprised of healthcare organizations (eg, hospitals, EMS, public health) within a geographic area. ${ }^{9}$ The HCCs integrate with Emergency Support Function (ESF)-8 (Public Health and Medical) activities and incident command system (ICS) responsibilities. In addition, each state develops guidance for crisis standards of care (CSC) with input from local and regional authorities. ${ }^{10}$ State public health will enact CSC operations emergency declarations to protect the public and healthcare personnel (HCP) in situations when resources are impacted or limited. ${ }^{10}$

The ICS under the Command and Management component of NIMS provides the basis for HICS and creates a management system that provides a coordinated institutional response to any emergency, including an infectious disease outbreak within a facility. ${ }^{11}$ When activated for an outbreak, HICS is meant to optimally leverage available resources, allow personnel to organize in a manner that allows them to achieve a desired outcome, and prevent discord and confusion when operating under stressful conditions. ${ }^{12}$ Both NIMS and HICS involve common terminology, a specific chain of command, management sections, and emergency response roles. There are 5 major sections within the HICS $^{6,7}$ :

1. Command

2. Operations

3. Planning

4. Logistics

5. Administration/Finance

The HICS structure facilitates rapid integration of multifaceted response elements within a facility, allowing each group (eg, infection prevention and control, public affairs, supply chain management) to work within its area of expertise while accessing the information and operational capabilities of other groups in an efficient and organized manner. Because most organizations with responsibilities in incident management employ an incident command system (ICS), HICS facilitates communication with external groups and agencies. ${ }^{5,13}$ 


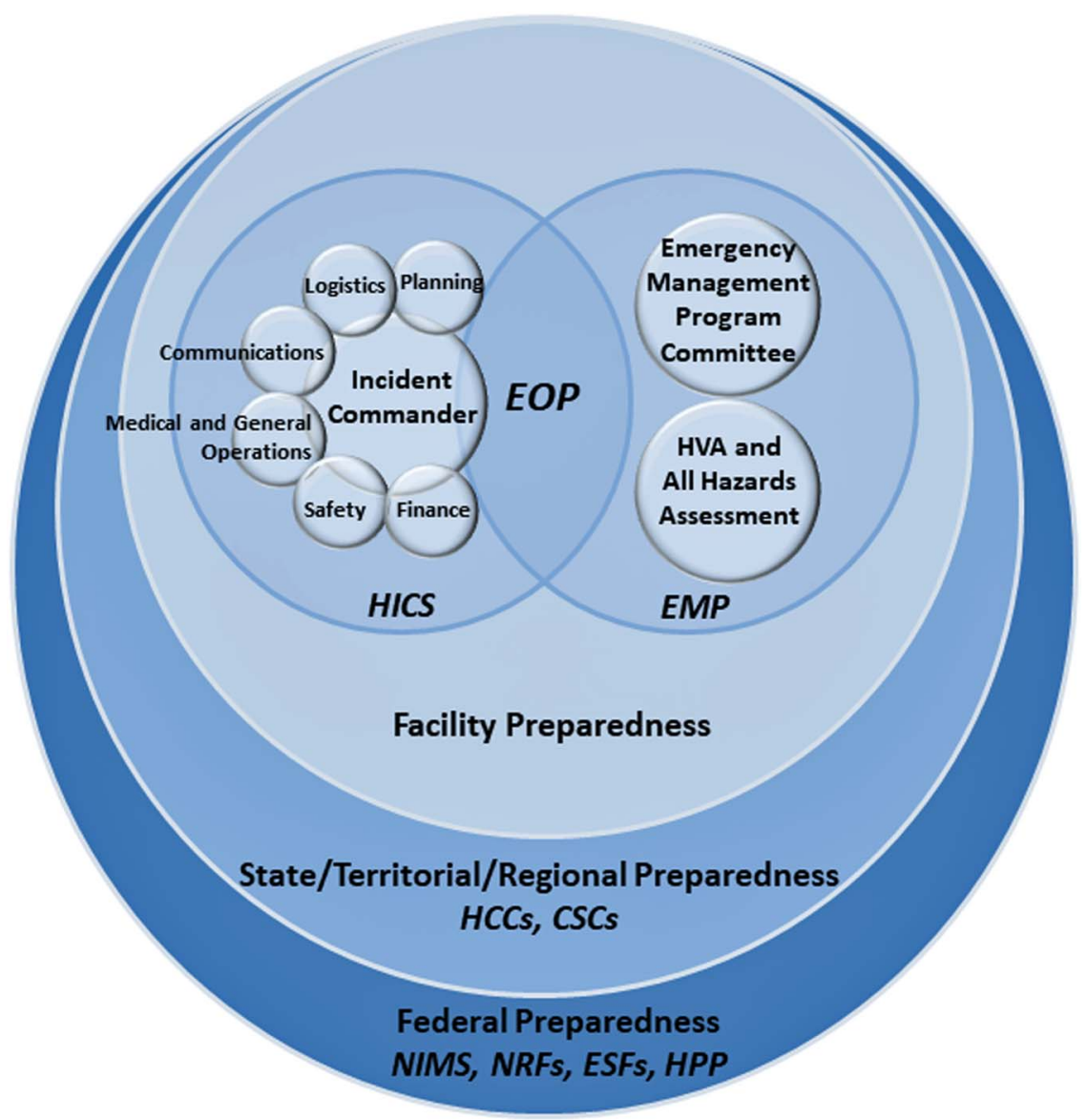

FIGURE 1. Diagram of incident management preparedness structures and frameworks. This diagram was created by the authors of this expert guidance document to illustrate how US preparedness structures and frameworks relate, starting at the federal level and moving to the facility level. Legend: National Incident Management System (NIMS), National Response Framework (NRF), Emergency Support Function (ESF), Hospital Preparedness Program (HPP), Health Care Coalition (HCC), Crisis Standards of Care (CSC), Hospital Incident Command System (HICS), Emergency Management Program (EMP), Emergency Operations Plan (EOP).

During HICS activation, the hospital may need to activate different response elements within the structure, depending on the nature of the event and the operational needs of the facility. The effectiveness of HICS relies on the familiarity of staff in working within the structure, provided through training, routine exercises, and activation for incidents that require a rapid and multifaceted institutional response. ${ }^{13-15}$

HICS is managed by the Hospital Incident Management Team (HIMT) (Figure 2), whose responsibilities are defined with job action sheets (JASs) that can be amended to fit a scenario. The facility identifies an appropriate physical space for the HIMT to meet during HICS activations, called the hospital command center (HCC). ${ }^{6}$

A facility's Emergency Management Program (EMP) sets the goals and vision for handling crises, builds on the 4 phases of incident management, and informs HICS ${ }^{6,16}$ :

1. Preparedness: Planning the actions needed in the case of an emergency or threat.
2. Mitigation: Prevention of an emergency or efforts to reduce the damage from a hazard.

3. Response: The activities that occur during an emergency.

4. Recovery: The actions needed following an emergency to return to normal.

The EMP is informed by a Hazard Vulnerability Analysis (HVA) (also known as a risk assessment), which highlights potential hazards, their likelihood and impact, and the vulnerabilities a facility may have in the setting of such a hazard, and an All-Hazards Self-Assessment of the facility's operational needs to fulfill its core mission of patient care during an incident, regardless of the nature of the incident. ${ }^{16,17}$

The EMP is overseen by an Emergency Program Manager and Emergency Management Committee, which create the Emergency Operations Plan (EOP) that details a facility's plan for responding to and recovering from threats and helps organize the structure of the hospital response, including the execution of HICS during an incident. ${ }^{12}$ The EOP is comprised 


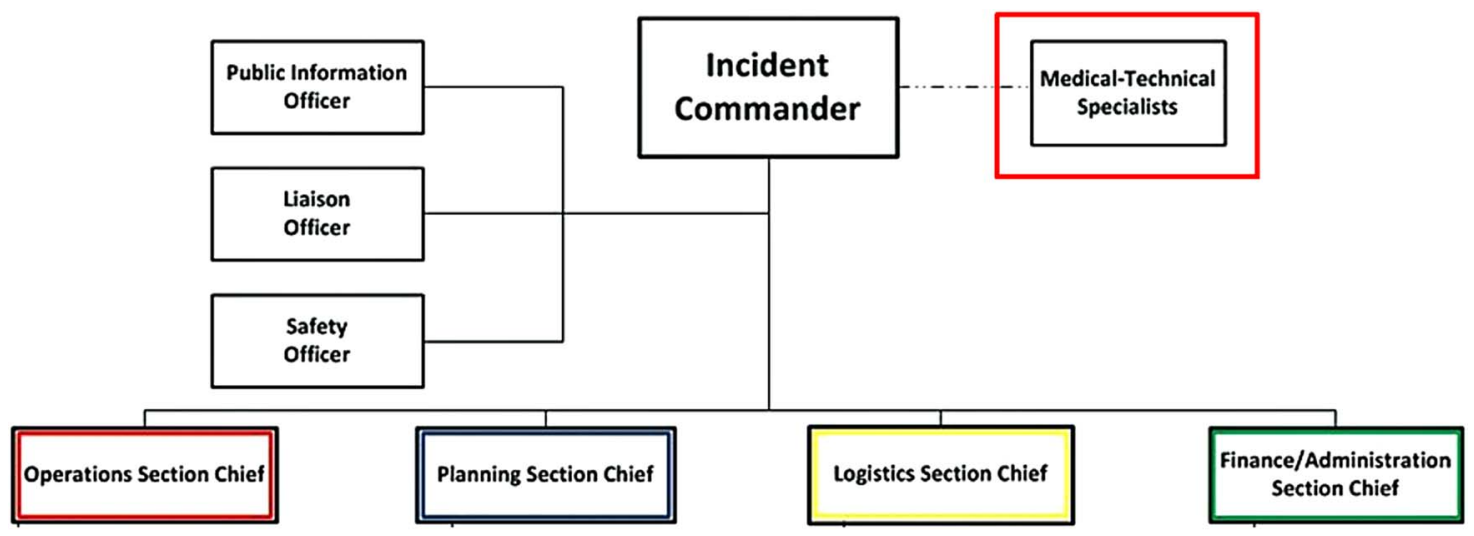

FIGURE 2. Hospital incident management team (HIMT). From the HICS guidebook ${ }^{6,7}$ (p. 45):

- Incident commander (IC): Oversees operation; determines which parts of the plan will be activated.

- Public information officer (PIO): Provides information updates to internal and external stakeholders.

- Liaison officer (LO): Conduit between hospital and outside agencies.

- Safety officer (SO): Responsible for safety of hospital staff, visitors, and patients; monitors response and anticipates hazardous conditions or situations.

- Medical-technical specialist (likely role of the HE): Assists the incident commander by providing event-specific advice and counsel.

- Operations section chief: Develops and implements strategies and tactics carried out by the incident commander, i.e., staging, medical care, infrastructure, security, hazardous materials, and business continuity.

- Planning section chief: Oversees incident related data gathering and analysis and develops alternatives for tactical operations and preparing the incident action plan for each operational period.

- Logistics section chief: Obtains necessary resources needed by operations and planning; supervises damage reporting and control, sanitation, supply, transport, and nutrition.

- Finance/Administration section chief: Monitors cost related to the incident; accounting, procurement, and analyses.

of 6 critical components, as required by the Joint Commission's Emergency Management Standards ${ }^{18}$ :

1. Communications

2. Resources and assets

3. Safety and security

4. Staff responsibilities

5. Utilities

6. Clinical and support activities

Rather than creating a different plan for every possible extraordinary event, the basic response elements that are common to most potential incidents form the backbone of preparedness within the EOP. In addition, the EOP includes several other elements:

1. Plans that address different categories of incidents (eg, emerging pathogens, radiation events, chemical events, mass casualty events). Within the category of biologic events, such as influenza pandemics or outbreaks of emerging pathogens, the EOP leverages commonalities between microorganisms (eg, mode of transmission, laboratory risk, waste management needs). ${ }^{17}$

2. Protocols for coordinating with external entities

3. Personnel training

4. EOP implementation plan ${ }^{9}$

5. Review and evaluation of the EOP
Federal and state guidance documents and tools are available to help facilities create and assess the adequacy of their EOPs, ${ }^{19}$ and outline operational aspects of response, including activation of the EOP, staffing considerations, communication needs, infection prevention and control, and postmortem care. ${ }^{17}$

\section{Stakeholders in Preparedness and Response}

\section{Recommendations.}

1. The healthcare epidemiologist (HE) should create, maintain, and/or have access to a list with contact information for individuals and groups/organizations relevant to his/her role in outbreak response, and establish lines of communication with these stakeholders.

2. The HE should be familiar with facility, local, and state practices and protocols for interaction with stakeholders, which may vary depending on location.

Rationale. Successful incident management requires the expertise of numerous internal and external stakeholders (Table 2), with coordination from facility leadership and adherence to communication protocols. ${ }^{20-23}$ For the purposes of this document, the authors define internal stakeholders as parties within the facility that can affect or be affected by the outbreak. Internal stakeholders vary depending on the 
TA вLE 2. Stakeholders and Resources in Incident Management ${ }^{\mathrm{a}}$

Internal

Patients

(no contact list)

Direct care HCP

(no contact list)

Clinical leadership

Administrative leadership

Support services leadership

Facility services leadership
- Patients

- Patients' families

- Visitors

- Community

- Physicians

- Nurses

- Allied health practitioners

- Medical and nursing

- Critical care

- Infectious diseases

o Obstetrics

$\circ$ Medicine

○ Pediatrics

- Radiology

o Surgery

○ Trauma

- Allied health (OT/PT/RT)

- Emergency department leads

- Community infectious diseases physicians who would act as medical-technical specialists in HIMT

- Volunteer services (facility and emergency response)

- Facility

○ President/Chief executive officer

- Director of nursing

- Chief medical officer

o Chief safety officer

- Risk manager

- Vice president of finance

- Communications

- Health incident management team (HIMT)

$\circ$ Incident commander (IC)

- Public information officer (PIO)

- Liaison officer (LO)

- Safety officer (SO)

- Medical-technical specialist

o Operations section chief

- Planning section chief

$\circ$ Logistics section chief

o Finance/Administration section chief

- Recovery coordinators

- Academics, if applicable

o Dean of students

o Student health medical director

- Infection prevention and control

- Environmental services

- Food services

- Information technology and health information systems

- Security

- Materials management

- Ethics

- Laboratory operations

○ Microbiology

- Blood bank

- Other laboratory divisions as appropriate

- Dialysis

- Diagnostic imaging

- Occupational health and safety

- Ambulance services

- Pharmacy 
TABLE 2. Continued

External

Public health/departments of health - Health care coalition (HCC): Healthcare organizations and public health officials within a geographic area, conducts preparedness and surge capacity exercises, collaborates with Emergency Support Function (ESF)-8.

- State/Territorial/Regional/Tribal

$\circ$ Contacts at the local health department. These contacts can assist with contacting the state laboratory contacts or the Centers for Disease Control and Prevention (CDC).

- State epidemiologists

- Director of health and nursing leadership

- Public health laboratory leadership

- Federal

o Department of Health and Human Services (HHS)

- CDC

- Laboratory response network (LRN): Integrated network of state/local public health, federal, military, and international laboratories created to respond to bioterrorism, chemical terrorism, and other public health emergencies.

- 24/7 Emergency Operations Center (EOC) Watch Desk

- National Institutes of Health (NIH)

- Assistant Secretary for Preparedness and Response (ASPR) Hospital Preparedness Program (HPP): Federally funded program to support regional healthcare system preparedness ${ }^{9}$

$\circ$ Emergency support functions

- ESF-8 (Public health and medical services)

- ESF-1 (Transportation)

- ESF-3 (Public works and engineering)

- ESF-5 (Emergency management)

Regional healthcare organizations/ facilities

Municipality leadership

Unions

Nongovernmental organization (NGO) contacts

Public and media

(no contact list)
- Health care coalition (HCC)

- Hospitals

- Postacute-care facilities

- Long-term-care facilities

- Healthcare networks

- Designated specialty care centers

- Healthcare providers

- Clinical care centers

- Mayor

- Emergency medical services

- Fire and rescue

- Law enforcement

- Public works

Relevant union(s) based on facility

- Volunteer/donation supported organizations (eg, Red Cross, Salvation Army)

- Faith-based organization(s)

Coordinated through public information officer (PIO)
Resources and Assets

Facility

Equipment

Medical supplies

\section{Examples}

- Floor plans

- Generators

- Heating, ventilation, and air conditioning (HVAC) systems

- Power

- Sanitation

- Ventilation

- Water

- Beds

- Extracorporeal membrane oxygenation (ECMO) equipment

- Hemodialysis equipment

- Ventilators

- Personal protection equipment (PPE)

Type

○ Quantity on site

$\circ$ Quantity stockpiled

- Reusable medical equipment (RME)

- Alcohol-based hand rub (ABHR) stations 
TABLE 2. Continued

\begin{tabular}{|c|c|}
\hline Resources and Assets & Examples \\
\hline Private or academic research centers & $\begin{array}{l}\text { - Rapid diagnostics } \\
\text { - Treatment } \\
\text { - Technology that may not be ordinarily available }\end{array}$ \\
\hline Training, education, and toolkits & 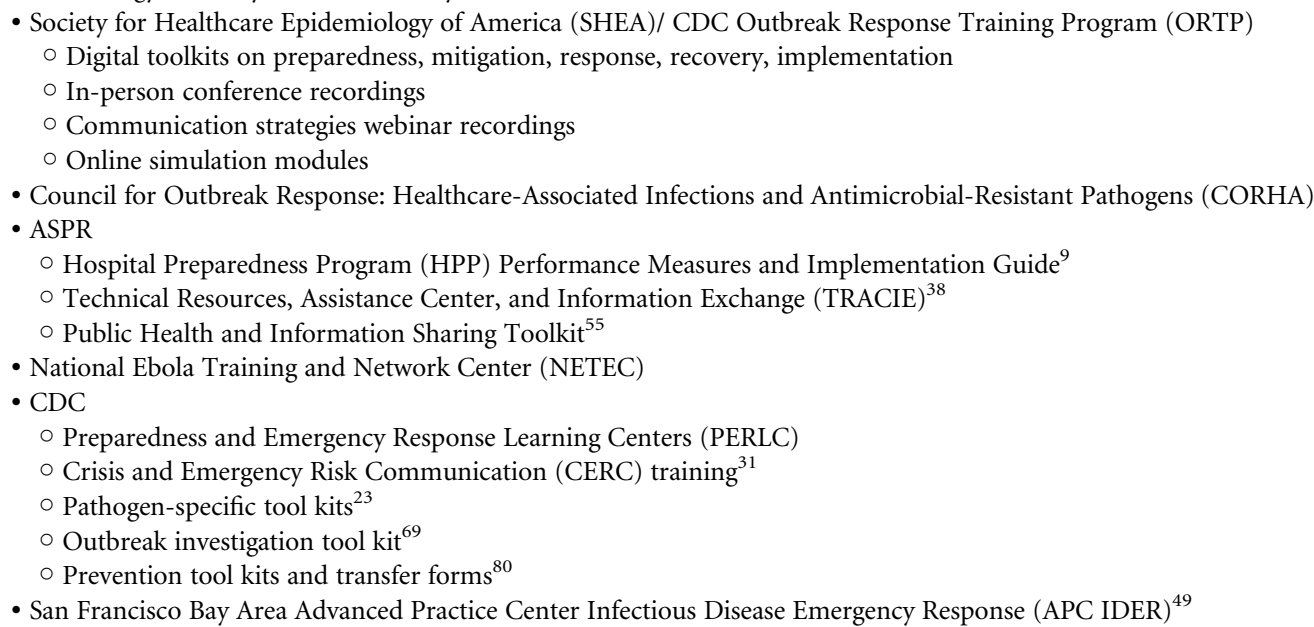 \\
\hline
\end{tabular}

${ }^{a}$ Hospital epidemiologists should obtain contact information for individuals or groups whose information is available and can be maintained. Individual contacts may change, so permanent office lines should be included. While each stakeholder and resource may not be needed in every outbreak, all should be identified during preparedness. ${ }^{24,}{ }^{44}$ Additional stakeholders and resources may be needed and/or available depending on the facility.

Patients, visitors, and direct care personnel, while stakeholders, are too numerous and frequently changing to be maintained by the HE for the purposes of an incident management contact list.

situation (eg, specific pathogen, mode of transmission, number of patients involved, severity of illness, geographic distribution of cases). The authors define external stakeholders as organizations, agencies, groups, and individuals external to the facility whose engagement may be required for effective outbreak response.

Internal stakeholders in incident management, in addition to patients, visitors, and volunteers, can be broadly divided into several categories (Table 2$)^{24}$ :

1. Direct care providers (eg, physicians, nurses, allied health practitioners)

2. Administration (eg, hospital executive, risk management, communications, financial leadership)

3. Support services (eg, environmental services, food services, security)

4. Facility services (eg, laboratory, diagnostic imaging, occupational health)

An organizational chart for outbreak response, eg, the CDC Hospital Pandemic Influenza Planning Checklist, may assist in defining stakeholder roles and responsibilities. ${ }^{24,25}$ The composition of the team of internal stakeholders may vary depending on the type and scale of the outbreak and the specific pathogen. Responsibilities should be defined in relevant policies and procedures and reflect members' content expertise, as well as role in planning, implementation, and response.

An emerging pathogen outbreak usually requires resources and expertise beyond the facility's internal stakeholders, in part because of the rapidly evolving nature of the outbreak, the likelihood that multiple jurisdictions will be affected, and the speed and consistency needed for guidance and policy development and implementation. External stakeholders include health authorities at the state/territorial/regional level, including HCCs, and federal levels, who may lead coordination across public and private sectors (Table 2). ${ }^{10,26-28}$ Depending on the pathogen, the breadth of stakeholders may expand or contract. In the case of pathogens resulting in imported US cases with the potential for local and sustained human-to-human transmission (eg, SARS, MERS-CoV, EVD), the response may include involvement of the US National Response Framework (NRF)'s Emergency Support Functions (ESFs) for interagency response to states, including Emergency Support Function (ESF)-8 (Public Health and Medical Services), ESF-1 (Transportation), ESF-3 (Public Works and Engineering), ESF-5 (Emergency Management), and/or others. Activating state and/or federal ESFs require state emergency management or FEMA. State and local emergency management should be contacted if a facility 
determines ESFs are needed. State emergency management would serve as the conduit for FEMA if federal ESFs are needed.

\section{Communication Strategies}

\section{Recommendations.}

1. Facilities should employ communication standards described in NIMS, which recommends common or plain language used across systems (emergency management, law enforcement, emergency medical services, fire department, and public health agencies).

2. Facilities should adhere to the 6 principles of CDC's Crisis and Emergency Risk Communication (CERC).

3. The HE should be trained in CERC, which can be accomplished through in-person and online training.

Rationale. In public health emergencies, including emerging pathogen outbreaks, effective communication to stakeholders and the community at large requires use of common language. NIMS provides core concepts, principles, terminology, and organizational processes for both internal and external communications regardless of the cause, size, location, or complexity of the situation. ${ }^{5}$ Internal communications make staff situationally aware by confirming the nature of the threat, what is currently known about the threat, and the resources committed. Communications with external audiences provide updates and direction for the audience. ${ }^{29,30}$ In most cases, external communication is handled by a public information officer (PIO) in HICS to maintain consistency of message and centralized knowledge of information and resources shared or requested. ${ }^{6}$ The facility should anticipate and plan for follow-up questions on background, implications of the outbreak, and speculations. ${ }^{4}$ The CDC's CERC combines elements of crisis communication (informing or alerting the community of an emerging pathogen) and risk communication (providing the community with information about the expected type and magnitude of an outcome), giving a set of principles that teach effective communication before, during, and after an emergency. ${ }^{31}$ CERC also addresses how to communicate effectively in situations of evolving guidance and findings, and addresses the imperfect nature of choices made during a crisis. ${ }^{31}$ The principles of CERC have been defined as follows:

1. Be first

2. Be right

3. Be credible

4. Express empathy

5. Promote action

6. Show respect

\section{Legal, Ethical, and Regulatory Requirements}

\section{Recommendations.}

1. Federal, accrediting, state, and local/regional bodies set requirements/standards pertinent to infectious diseases outbreaks, which may change or be updated due to anticipated, occurring, or past outbreaks. Requirements should be identified in the facility's EMP, which should incorporate these 2 elements:

a. Public health structures that influence delivery of care during an outbreak investigation and/or declared public health emergency.

b. Regulations that influence delivery of care around facility and emerging pathogen outbreaks, as well as declared public health emergencies.

2. The facility should ensure hospital legal counsel (or equivalent) is part of the HICS structure.

3. The facility's Ethics Committee (or equivalent) should be involved in EMP and EOP reviews, especially when plans deviate from accepted standards of clinical care.

4. The facility should be aware of its state's "crisis standards of care" (CSC) guidance when outbreaks limit the resources needed to provide the usual standard of care.

Rationale. The first line of contact in the response to an outbreak is the state/territorial/regional public health authority. A number of laws and regulations exist at each level relating to outbreak investigation and incident management in a public health emergency. Public health events (eg, 2003 SARS epidemic, 2009 influenza A (H1N1) pandemic, and 2013-2014 EVD epidemic) led public health officials to strengthen their jurisdictions' legal preparedness for all types of public health emergencies. ${ }^{32,33}$ Specific to federal authorities, a compilation can be found in the CDC publication "Selected Federal Legal Authorities Pertinent to Public Health Emergencies." 34

These laws overlap with important ethical principles central to the care of patients in public health emergencies. Specific to EVD, the Centers for Medicare and Medicaid Services (CMS) published the "Emergency Medical Treatment and Labor Act (EMTALA) Requirements and Implications Related to EVD," which states that every hospital must provide appropriate screening, treatment, and isolation as needed for all individuals who come to the emergency department (ED), including those suspected of having been exposed to EVD, regardless of whether they arrive by ambulance or are walk-in patients. ${ }^{35} \mathrm{CMS}$ does allow for local authorities with responsibility for multiple hospitals to designate Emergency Medical Services (EMS) response to specific hospitals when EVD is considered possible.

In November 2016, CMS published its "Emergency Preparedness Requirements for Medicare and Medicaid Participating Providers and Suppliers." ${ }^{36}$ In November 2017, these regulations will apply to 17 Medicare and Medicaid providers types with requirements under 4 core elements of emergency preparedness $^{37}$ :

1. Risk assessment and emergency planning

2. Communication plan

3. Policies and procedures

4. Training and testing 
Numerous checklists summarize requirements for HCP under this rule. ${ }^{37,38}$

Using EVD as an example of an emerging pathogen outbreak response, CMS provides requirements of clinical care to be provided through the EMTALA, also supported by Joint Commission's Standards to guide how to manage a person under investigation (PUI). ${ }^{35,39}$ Facilities are required to provide the following:

a. Medical screening examination (MSE)

b. Risk assessment

c. Triage

d. Care using effective personal protective equipment (PPE)

The Joint Commission amended and revised its requirements related to emergencies to bring those regulations into line with the NIMS/HICS framework. The requirements include (1) identifying a leader to oversee emergency management, (2) seeking staff input when evaluating exercises and responses to events, and (3) involving senior leadership. ${ }^{4,39}$

The facility's Ethics Committee (or equivalent) should provide early consultation, particularly in situations when standards of care may be altered based on the pathogen. In addition, the facility should understand and be able to access resources relevant to its state's CSC, based on the 2009 Institute of Medicine (IOM) guidance for situations that cause substantial changes in operations and the ability for the facility to provide established levels of care. Crisis standards of care provide an ethical framework for stewardship of limited resources. ${ }^{38,40}$

Roles and Responsibilities of the Healthcare Epidemiologist in Facility and Emerging Pathogen Outbreaks

For the purposes of this document, the authors consider a facility outbreak to be a situation in which the number of cases of infection exceeds the facility's normal baseline and intrafacility transmission is suspected or proven. Even a single case may be considered an outbreak if normally there are no cases (eg, healthcare-associated legionella infection). The authors use the 1992 IOM report definition of an emerging pathogen as a new, reemerging, or drug-resistant infection with an incidence in humans that has increased within the past 20 years or threatens to increase in the near future. ${ }^{1}$

This section addresses the role of the HE, as well as roles and responsibilities of the facility and direct care $\mathrm{HCP}$, to provide context regarding the division of labor and team responsibilities during incident management and outbreak response.

\section{Leadership Role of the HE in Incident Management}

\section{Recommendations.}

1. The HE should be versed and trained in basic HICS response.

2. In most facilities, the HE serves as the medical-technical specialist in domains relevant to infection prevention and control and infectious diseases within HICS when the system is being utilized.
3. The HE should ensure that liability coverage is provided for the duties undertaken based on his/her role in HICS.

Rationale. Under HICS, in most facilities the HE operates within the command staff as the medical/technical specialist within the HIMT (Figure 2), offering scientific advice to the incident commander (IC) and safety officer, assisting the section chiefs and liaison officer (LO) with identifying risk mitigation and response options, and providing input to the public information officer (PIO) on communications. ${ }^{6,7}$ In smaller cluster investigations, when HICS has not been activated or in situations where the HE has additional training or expertise in incident management, he/she may assume other roles, including that of the IC.

The HE should have a working knowledge of HICS to provide expertise and oversee the infection prevention and control components of the EOP. FEMA provides training opportunities for HCP with a direct role in emergency preparedness, incident management, and/or emergency response. ${ }^{15}$ The facility should define the HE's role during planning for facility and emerging pathogen outbreaks within job action sheets (JAS). ${ }^{13}$ This role may involve several elements ${ }^{25}$ :

1. Providing advice and direction to the facility leadership and the multidisciplinary team managing the outbreak.

2. Drafting clinical guidance in directing the response to a facility outbreak.

3. Providing input into clinical operations.

4. Evaluating management options for addressing clinical issues.

5. Reviewing messages that will be provided to the public for accuracy and clarity.

6. Reviewing communications to the professional medical community to ensure accuracy and acceptance by participating responders.

7. Alerting the facility's emergency management leadership regarding the need and timing for HICS activation in response to an infectious diseases outbreak.

During facility and emerging pathogen outbreaks, while HEs may provide clinical care to individual patients, they should not be required to do so unless dictated by the clinical schedule, and should be relieved of clinical duties if possible. ${ }^{2}$ The HE may not be covered under the facility's risk management structure or liability insurance, and he/she should ensure that coverage is provided by the facility for roles undertaken during outbreak response and incident management. ${ }^{12,41}$

\section{Activities and Responsibilities of the HE in Incident Management}

\section{Recommendations.}

1. The HE should provide input into the facility's EMP and the 4 phases of incident management as they relate to 
infectious diseases and infection prevention and control: preparedness, mitigation, response, and recovery (Table 3 ).

2. The HE should be involved in the development, maintenance, and evaluation of a facility's EOP as it relates to infectious diseases outbreaks.

3. The HE should ensure that the hospital systematically monitors local, federal, and international public health advisories and alerts of emerging pathogens.

4. The HE should ensure the existence of, or help develop when needed, a hospital-wide surveillance program that accurately and rapidly identifies exposed and infected patients and HCP, including protocols for reporting these individuals to infection prevention and control staff.

5. The HE should interpret advisories/alerts and surveillance data to identify when the healthcare facility is faced with a potential or actual outbreak, and report this information to the Emergency Program Manager, the Incident Commander (IC), and/or appropriate leadership as established by the facility.

6. The HE should have access to contact information for, and have working knowledge of, stakeholders' roles in responding to a facility or emerging pathogen outbreak (Table 2).

7. The HE should ensure that the facility develops easily accessible and widely disseminated written multidisciplinary protocols for identifying, investigating, responding to, and containing facility and emerging pathogen outbreaks.

8. When HICS is activated, the HE should provide the Incident Commander (IC) with situational awareness to contribute to the common operating picture (COP) of the crisis.

Rationale. Many resources describe the specifics of how to manage patients with a variety of infectious diseases, including the infection prevention and control elements; however, knowledge of guidelines and guidance are insufficient to prepare the HE for the complexities of managing a facility-level or emerging pathogen outbreak. To optimize the facility's ability to manage an infectious disease outbreak, the HE should work with the EMP, Emergency Management Committee, relevant planning committees (eg, regional emergency preparedness committees), emergency department staff, and public health departments to assess how to adapt the EMP to respond to infectious disease emergencies. The HE should be involved in the development, maintenance, and evaluation of the facility's EOP as it relates to infectious diseases and should provide input into modifications needed to address specific infectious diseases.

Resources from CDC and The Joint Commission provide guidance on core components of the EOP and tools to assess plans. ${ }^{17,39,42}$ Specifically, the HE may provide input to the EMP and EOP in the following areas ${ }^{42-45}$ :

1. Surveillance to detect and report infectious diseases threats. ${ }^{17}$

2. Policies and procedures including, but not limited to, screening and triage, patient placement, cohorting, transport, patient care, environmental decontamination, and postmortem care.

3. Triage of patients, HCP, visitors, and volunteers. ${ }^{46}$

4. Hospital readiness related to infection prevention, such as availability of isolation rooms, PPE, and hand hygiene products and stations.

5. Patient populations that may be disproportionately impacted (eg, children, immunocompromised patients, pregnant women).

6. Education for HCP, including physicians, direct care $\mathrm{HCP}$, indirect care HCP, students, and volunteers.

7. Occupational health policies and procedures including but not limited to nonpunitive sick leave and postexposure prophylaxis.

8. Surge capacity

9. Protocols for specific pathogens ${ }^{46}$

10. Communication protocols, to include coordination and communication with local, state, and federal agencies. ${ }^{5,31}$

11. Information management

12. Laboratory issues

13. Immunoprophylaxis, chemoprophylaxis, and antiinfective treatment

14. Physical plant, including but not limited to waste management

15. Exercises/drills to test and update the EOP

\section{Role of the HE in Coordination with Stakeholders}

\section{Recommendations.}

1. When HICS is activated, the HE should assist the IC and the PIO in creating and/or reviewing messaging for internal and external stakeholders. If HICS is not activated, the HE will assist designated facility communications leadership.

2. The HE should work collaboratively with internal and external stakeholders to coordinate the outbreak response in accordance with his/her designated role within HIMT (Table 2).

Rationale. As part of preparedness, the HE should identify internal and external stakeholders before an incident occurs, to include communications personnel/PIO, senior leadership of the facility (eg, President/Chief Executive Officer, Director of Nursing, Chief Medical Officer, Chief Information Officer), the local health department, and other community contacts (Table 2). External stakeholders may include local, state/territorial/regional, and federal health departments, reference laboratories, and local hospitals. The Hospital Pandemic Influenza Planning Checklist assists in identifying potential contacts. ${ }^{4,44}$

The HE should inform staff via established protocols of the status of an outbreak response. When HICS is activated, the HIMT liaison officer will be responsible for updates to and correspondence with stakeholders. ${ }^{11}$ The response and 
TABLE 3. Activities of the Hospital Epidemiologist in Incident Management ${ }^{\mathrm{a}}$

Phase Example Activities ${ }^{\mathrm{b}}$

HE Role in EMP and EOP

Preparedness: Planning actions needed in the case of an emergency or threat

Mitigation: Prevention of an emergency or efforts to reduce the damage from a hazard

Response: Activities that occur during an emergency
- Identify strengths and/or gaps as they relate to infectious diseases outbreaks

- Bring forward for specific consideration and training findings of infection prevention and control assessments that show potential vulnerabilities or weaknesses, eg, hand hygiene compliance or environmental cleaning

- Identify and/or establish protocols within the facility's EOP as they relate to outbreak or emerging pathogen management:

$\circ$ Policies for specific pathogens

- Environmental decontamination

○ Environmental safety

$\circ$ Respiratory etiquette

- Evaluation, diagnosis, and management of patients, including screening, triage, placement, transport, care

- Surveillance and triage of $\mathrm{HCP}$, volunteers, patients, and visitors

- Patient populations that may be disproportionately impacted by a threat (eg, children, immunocompromised patients)

- Transfer policies (eg, LTCF or specialized facility)

- Postmortem care

- Information security

- Identify and establish points of contact, stakeholders, and resources (Table 2)

- Provide input into infection prevention and control education and training for $\mathrm{HCP}$, including direct patient care HCP, clinical staff, laboratory staff, housekeeping, emergency personnel, and environmental services, especially in measures such as hand hygiene, respiratory etiquette, and isolation

- Provide input into exercises/drills to test EOP

- Provide input regarding resource and staffing needs, including the potential for enhanced supports for laboratory, housekeeping, and environmental services.

- Provide input into occupational health considerations, including nonpunitive sick leave, furlough, quarantine, and postexposure prophylaxis so that the facility can maintain:

o Rapid identification of potentially exposed patients/staff/visitors and create line list of those individuals

- Notification of exposed individuals, with proper documentation

$\circ$ PEP for exposed individuals

- Tracking of HCP work

- Approval of communications by appropriate individuals (eg, PIO, Risk Management)

- Ensure adequate surveillance and detection for infectious diseases threats (eg, syndromic surveillance, monitoring national and global epidemics)

- Plan how patients with a suspected or confirmed infection would be isolated or cohorted

- Evaluate and recommend alternative management strategies based on the suspected mode of transmission

- Work with staff/HIMT to ensure adequate supplies of PPE (respiratory protection, eye protection, impervious body coverings, gloves), isolation rooms, and hand hygiene stations and products, and PPE stockpile

- Work with staff/HIMT in design and/or implementation of HCP training on PPE use

- Manage HCP exposures

- Input into quantity needed for disposable and nondisposable supplies and equipment and adequate numbers of RME

- Provide guidance in cleaning and disinfection of RME and the environment

- Input into strategy for continuing activities in the setting of limited supply quantities

- Fill role of medical-technical specialist in HIMT (most likely role of the HE), providing expert medicaltechnical content

- Identify/draft clinical guidance pertaining to pathogen, eg, screening/triage protocols, care protocols, isolation

- Adjust clinical and support activities depending on mode of transmission

- Monitor the incident for infection prevention and control implications

- For HCP, patient, and visitor post-exposure management:

$\circ$ Identify and line-list all potentially exposed $\mathrm{HCP} /$ patients/visitors

- Work within structure to notify all exposed individuals

- Determine whether post-exposure prophylaxis is available and indicated

- Determine whether exposed individuals need to be furloughed or quarantined

- Supervise tracking and documentation of all post-exposure management activities, including exposure notification 
TABLE 3. Continued

\begin{tabular}{|c|c|}
\hline Phase & Example Activities $^{\mathrm{b}}$ \\
\hline $\begin{array}{l}\text { Recovery: Actions needed following an emergency to } \\
\text { return to normal }\end{array}$ & 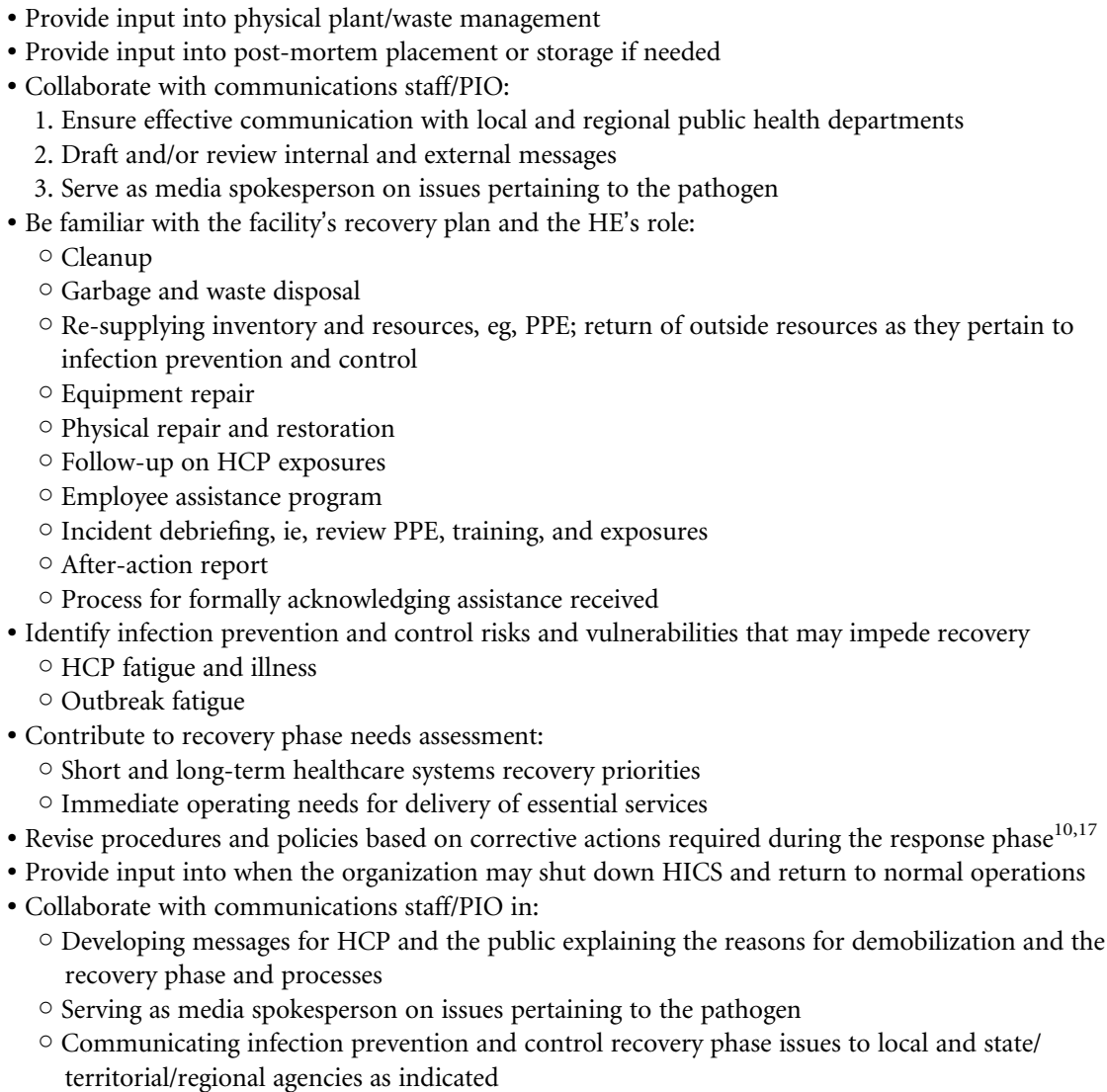 \\
\hline
\end{tabular}

Regulations and Legal Considerations for the HE Preparedness

\section{Mitigation}

Response

Recovery

Resource Management

Preparedness

Mitigation

Response

Recovery
- Local public health laws (state/territorial/regional specific)

- CMS regulations related to specific pathogens ${ }^{35}$

- Joint Commission management of a PUI

Ensure liability coverage for duties undertaken in role of medical-technical specialist in HICS

Seek consultation with internal risk management, ethics specialists, and local and national public health authorities as needed

Input into how laws and regulations affected the response

- Develop strategies for dealing with limited/constrained resources and/or surge capacity

- Review "State Crisis Standards of Care"

- Input into inventory supplies at the facility

- Input into items needed from regional stockpile inventory, if necessary

- Work with staff to ensure adequate supplies of PPE (respiratory protection, eye protection, impervious body coverings, gloves), isolation rooms, and hand hygiene stations and products

Adapt airflow for surge capacity

- Contribute to recovery phase needs assessment:

$\circ$ Identification of facility's short and long-term recovery priorities

- Identification of immediate operating needs for delivery of essential services:

- Personnel

- Equipment

- Supplies

- Along with the facility recovery team, coordinate with internal and external stakeholders such as other hospitals in the network, local and state health departments, and nongovernmental stakeholders (eg, home care services, LTCF, Red Cross, etc.) to develop collaborative strategies for delivery of essential health services 
TABLE 3. Continued

\begin{tabular}{|c|c|}
\hline Phase & Example Activities ${ }^{b}$ \\
\hline \multicolumn{2}{|c|}{ Clinical Research Related to the $\mathrm{HE}^{\mathrm{c}}$} \\
\hline \multirow[t]{3}{*}{ Preparedness } & - Identify local investigators \\
\hline & - Identify key personnel to assist with IRB or IND process \\
\hline & - Participate in webinars discussing research on emerging infectious diseases \\
\hline Mitigation & Identifying experimental vaccines or therapeutics for patients cared for within the HE's institution \\
\hline Response & $\begin{array}{l}\text { Participating in clinical research within the institution, including administration of experimental } \\
\text { vaccines or therapeutics, obtaining clinical samples, and conducting chart reviews as part of approved } \\
\text { studies }\end{array}$ \\
\hline Recovery & $\begin{array}{l}\text { - Publishing findings of event evaluations as appropriate } \\
\circ \text { After-action report } \\
\circ \text { Corrective action plans }\end{array}$ \\
\hline
\end{tabular}

NOTE: HE, hospital epidemiologist; EMP, emergency management program; EOP, emergency operations plan; HCP, healthcare personnel; LTCF, long-term-care facility; PEP, postexposure prophylaxis; PIO, public information officer; HIMT, hospital incident management team; PPE, personal protection equipment; RME, reusable medical equipment; CMS, Center for Medicare and Medicaid Services; PUI, person under investigation; HICS, hospital incident command system.

${ }^{a}$ Activities may vary based on facility structure and needs. Many of these responsibilities may be shared or assigned to other facility or incident

notification footprint may differ depending on the outbreak, eg, MRSA cluster in a neonatal intensive care unit (NICU) contained within the facility, versus a norovirus outbreak with nursing home exposure that may require intervention and detection by the local health department, versus a measles or SARS cluster that would require state or federal involvement after the local public health department was notified.

In emerging pathogen outbreaks, the facility must ensure timely sharing of information and efficient responses both internally and externally. ${ }^{6}$ As the subject matter expert informing the HIMT, the HE may also serve as an external point-person for local, regional, and federal public health authorities. ${ }^{27,47}$

\section{Additional Resources and Assets for Outbreak Response}

\section{Recommendations.}

1. In coordination with the facility, the HE should know how to access and use the following resources for additional assistance:

a. The facility's HVA/risk assessment for most likely threats, to identify gaps

b. Office of the Assistant Secretary for Preparedness and Response (ASPR) Technical Resources, Assistance Center, and Information Exchange (TRACIE)

c. Internal and external stakeholders (see Table 2)

2. The HE should have knowledge of the following resources:

a. Regional centers with specialized capabilities for managing patients with suspected or confirmed infection with the pathogen of interest

b. Principles and processes related to transfer of care and coordination for EMS transport

Rationale. In the event of an infectious diseases outbreak, facilities may require additional resources, which should be identified through the facility's HVA/risk assessment and incorporated into preparedness efforts. ${ }^{25,48}$ The US
Department of Health and Human Services (HHS) ASPR TRACIE provides technical resources and assistance in emergency preparedness, including emergencies caused by emerging pathogens. ${ }^{38}$

In the EOP, the facility should identify regional specialty care centers for management of care, coordination of transport, and conservation of supplies and resources to streamline safe and effective care (Table 2). Additionally, the facility may have access to regional collaboratives and/or healthcare networks that can be utilized for standardization of policies and procedures and self-designation of centers for specialized services. ${ }^{10}$ Some organizations have developed toolkits to assist with accessing needed resources during an outbreak response. ${ }^{49}$

\section{Clinical and Support Activities}

\section{Recommendations.}

1. The HE should ensure that a facility's policies and procedures address, encourage, and facilitate infection prevention and control measures, including but not limited to hand hygiene, respiratory etiquette, and transmissionbased precautions.

2. The HE should be familiar with facility resources identified in the EMP, including

a. Number of isolation rooms and their locations

b. Plans and capability to adapt patient care rooms or units' airflow for surge capacity.

c. Cleaning and decontamination processes for both the environment and medical equipment.

d. PPE and medical supplies

3. In collaboration with the facility's Ethics Committee (or equivalent), the $\mathrm{HE}$ should provide expertise to leadership, or the IC when HICS is activated, in determining whether clinical care practices warrant modification or avoidance, depending on how the pathogen is transmitted, and 
whether additional measures or resources are needed to protect patients and HCP.

4. The HE should provide input to ensure that the facility:

a. Uses syndromic surveillance to detect an emerging pathogen outbreak in collaboration with and based on guidance from public health authorities.

b. Is prepared to provide a medical screening examination (MSE) of patients in clinical areas.

c. Provides critical care with appropriate PPE.

d. Places PUIs in private rooms as soon as possible until transfer to an appropriate isolation room, which may be in another center that has specialized capabilities, if needed.

e. Has appropriate environmental controls available, including rooms that meet airborne infection isolation specifications when airborne transmission may be a potential mode of transmission.

Rationale. At all times, a facility's policies and procedures should address, encourage, and facilitate infection prevention and control measures, including but not limited to hand hygiene, respiratory etiquette, and transmission based precautions. ${ }^{50}$ Healthcare organizations should have a hierarchy of controls to provide a safe workplace:

1. Engineering (eg, airborne isolation rooms, hand hygiene stations)

2. Administrative (eg, policies and procedures, including fitness to work)

3. The HE should collaborate with facility leadership/IC and provide guidance in the 4 phases of incident management as they relate to clinical and support activities, and infrastructure of the facility. ${ }^{33}$ The HE may be involved in recommending alternative management strategies and/or reallocation of resources:

1. Training of clinical, laboratory, housekeeping, and environmental services staff in infection prevention and control procedures pertinent to specific pathogens.

2. Providing protocols for use of equipment. When appropriate, disposable items should be used in caring for infected patients and PUIs. Items that are nondisposable should be dedicated for use only on the infected patient. ${ }^{51}$

3. Reviewing support activities for enhancement or adjustment based on the pathogen of concern and suspected mode of transmission, including but not limited to laboratory specimen handling and diagnostic testing, cleaning and decontamination processes, and waste management.

4. Assessing resource allocation to support outbreak management activities, including but not limited to laboratory, housekeeping, and/or environmental services, as dictated by the specific situation.

5. Reorganization, reassignment, or retraining of clinical and support staff.
6. Investigating and providing risk assessment for specific clinical activities if there is concern that a pharmaceutical, procedure, or medical device is causally linked to pathogen transmission.

7. Limiting number of staff caring for infected patients (eg, nurses, nursing assistants). ${ }^{23}$ Staff members who are ill should be excluded from work and non-essential staff, students, and volunteers may need to be excluded from areas in which infection transmission may be occurring. ${ }^{22}$

8. Temporary closure of an area of the facility. ${ }^{22,52}$

9. Utilization of information technology (IT) to provide electronic health records (EHR) alerts/flags for exposed people in their incubation period and screening or treatment algorithms within the EHR for triage.

The HE should be familiar with a facility's EMP, including clinical, core support, and infrastructure for the facility. Clinical services and infrastructure include, but are not limited to the following ${ }^{10,45}$ :

1. Clinical examinations: The facility should have syndromic surveillance in place to detect an emerging pathogen outbreak in collaboration with and guidance from public health authorities ${ }^{50}$ and be prepared to provide medical screening examination (MSE) for patients suspicious of infection with an emerging pathogen or highly transmissible infectious disease.

2. Respiratory therapy

3. Radiology

4. Trauma

5. Critical care

6. Pediatrics

7. Labor and delivery

8. Medication administration

9. Isolation capacity: PUIs should be placed in private rooms and facilities should provide critical clinical care with appropriate environmental controls and necessary PPE until transfer to centers with specialized capabilities. ${ }^{35,53,54}$

Core support services include the following:

1. Blood bank

2. Communications

3. Decontamination: Proper specimen handling (cleaning, disinfection, or sterilization) and environmental infection prevention and control procedures are important to prevent transmission of pathogens. ${ }^{42}$ For emerging pathogens, special facility arrangements may be needed for waste disposal, including linens and supplies, and processing effluents for specific pathogens. ${ }^{45}$

4. Human resources

5. Information systems: Leadership responsible for information technology and information management should minimize risks for data breaches that may compromise patient and staff confidentiality, which include the following: 
a. Coordinating and limiting communication and data to the minimum necessary for outbreak investigation and management. ${ }^{55}$

b. Monitoring access to patient health records and procedures for electronic communication with external laboratories or organizations involved in outbreak investigation to ensure electronic data transfer is adequately secured and encrypted.

6. Laboratory: Laboratory personnel can be particularly vulnerable during an emerging pathogen outbreak. The facility must notify and identify personnel who may be working with samples with transmission risks. Personnel must follow appropriate laboratory standards. The facility should train HCP and laboratory personnel in:

a. Appropriate selection and use of PPE, including donning and doffing procedures. ${ }^{57,58}$

b. Buddy systems and safety stops to prevent exposures and encourage safety.

During a potential or identified emerging pathogen outbreak, laboratory services should be coordinated within the framework of the CDC Laboratory Response Network (LRN). ${ }^{42}$ Due to the potential risk for laboratory specimens to be used in bioterrorism, the facility's laboratory should ensure security of specimens' containment and disposal. ${ }^{56}$

7. Mental health/psychology

8. Occupational health, ${ }^{10}$ including staffing models with considerations for:

a. Nonpunitive sick leave

b. Alternative ways to provide care, such as telemedicine, as a strategy to reduce potential HCP exposures

c. Post-exposure prophylaxis

d. Quarantine

e. Furlough

f. The potential for heat stress and fatigue with the use of PPE.

9. Pharmacy

10. Security: Facility safety and security concerns may arise during the investigation of an outbreak and the facility may need to limit or restrict visitation to protect patients and the public and minimize transmission risks, requiring collaboration with members of the HIMT and others, including the following ${ }^{59,60}$ :

a. Facility security and law enforcement agencies in situations where limitations are placed on patient and/or visitor movement. ${ }^{61}$

b. Communications leadership/PIO to maintain a high level of security when interacting with the media to preserve the privacy of hospital staff, patients, and their families.

c. A facility's EOP should encompass a security risk assessment of the physical plant and HCP, including the following:

i. Enactment of enhanced perimeter controls

ii. Restriction of visitation iii. Protection of resources (including stockpiled items) such as PPE, medications, and vaccines ${ }^{62}$

11. Transport

Facility infrastructure supports include the following:

1. Power

2. Water

3. Ventilation

4. Isolation rooms

5. Quarantine areas

6. Surge capacity

7. Morgue capacity

8. PPE: To limit spread through direct or indirect contact, the HE may need to initiate transmission-based precautions depending on the mode of transmission of the implicated microorganism. ${ }^{50}$ The EOP should estimate PPE needs and ensure adequate supply and during an outbreak audit staff use. ${ }^{63}$ Microorganisms transmitted through droplets and aerosols warrant the use of PPE, including masks (droplet spread) and N95 respirators or powered air purifying respirators (PAPRs) (aerosol spread). In past outbreaks, inconsistent use of PPE and lack of attention to proper doffing techniques was shown to lead to infection. ${ }^{54,64,65}$ As part of the preparedness phase, the facility should take the following steps:

a. Train HCP in donning and doffing techniques

b. Conduct fit testing of frontline HCP for N95 respirators

c. Train and certify HCP in the use of PAPRs, when appropriate.

Equipment and Supplies for Management of an Emerging Pathogen Outbreak

\section{Recommendations.}

1. As part of the EMP, the facility should undertake the following measures:

a. Maintain and make easily accessible an inventory of PPE and medical equipment that identifies what is on hand and what is needed for specific categories of emerging pathogen outbreaks.

b. Designate an individual responsible for maintaining levels of equipment, managing out-of-date supplies, and determining a plan to relay critical supply shortages to the local and state emergency response centers (eg, via the Logistics Section Chief in HIMT).

c. Identify and coordinate communication channels with other regional medical centers regarding equipment, supplies, and capacity for a regional response to an emerging pathogen.

d. Depending on the nature of the suspected pathogen, when possible and appropriate, utilize disposable medical equipment to minimize the need for decontamination. 
Rationale. Using an all hazard self-assessment, the hospital should identify risks and appropriate combinations of PPE items based on specific emerging pathogens, including the following ${ }^{17,45,66}$ :

1. Respiratory protection (eg, masks, respirators, PAPRs)

2. Eye protection (eg, face shields, goggles)

3. Impervious body coverings (eg, gowns, aprons, leggings, boots, head coverings)

4. Gloves

These items should be procured and stockpiled. Additional PPE may be required and designated personnel should ensure monitoring of supplies and a strategy for accessing PPE in a situation where quantities are limited. ${ }^{44}$

The CDC Hospital All Hazard Self-Assessment has a checklist for maintaining resources for emergency response. ${ }^{17}$ These include considerations for the following:

1. Use of disposable supplies and equipment over reusable medical equipment (RME) when managing highly transmissible pathogens. If RME must be used, the facility should consider having multiple pieces to cohort for known and/or suspect patients and reserve other equipment to maintain routine work flow.

2. Pathogen-specific indications for antivirals and vaccines. ${ }^{28}$

3. Telemedicine for patient care to reduce the amount of exposed equipment that requires decontamination, as well as PPE requirements.

4. Strategies to help maintain routine patient care activities (eg, using point-of-care testing for isolated patients to keep potentially highly infectious samples from contaminating laboratory equipment and allow for normal laboratory function; autoclave capabilities for medical waste) ${ }^{67}$

5. The number of ventilators (adult and pediatric) available in the facility.

6. The capacity of other regional medical centers to coordinate triage of patients when faced with surge events. ${ }^{17}$

Role of the HE in Experimental Vaccines, Therapeutics, and Clinical Research during an Emerging Pathogen Outbreak

\section{Recommendations.}

1. A facility, depending on its structure and resources, may engage in work on experimental vaccines, therapeutics, and/ or clinical research during an emerging pathogen outbreak. If the facility determines it may have a role in these activities, the facility should identify external partners, resources, and HCP roles during the preparedness phase and outline them in the EOP. The HE may assume a leadership role in such activities or the facility may designate another individual to assume this role, which may involve the following:

a. Collaboration with external partners, including HCCs or other state/territorial/regional public health authorities, industry, the US Food and Drug Administration (FDA), and facility structures such as the
Human Subjects Review Committee (or equivalent), to identify experimental vaccines or therapeutics that may be used.

b. Conduct of clinical research, conforming to all applicable regulations.

Rationale. Clinical research during an emerging pathogen outbreak can advance knowledge and provide potential countermeasures (medical and/or surgical) for affected individuals. Clinical research conducted during such periods must adhere to scientific and ethical standards. ${ }^{68}$

In an emerging pathogen outbreak, the HE may assume a role in approved clinical research that meets ethical and scientific standards (eg, identifying experimental vaccines or therapeutics, administration of experimental vaccines or therapeutics, obtaining clinical samples for analysis, and conducting chart review). Given the HE's potential leadership role in an emerging outbreak response, the HE may consider delegating clinical research to another qualified individual within the facility. This individual may be an infectious disease physician, infectious disease pharmacist, or other HCP with appropriate expertise and requisite clinical research experience and training (eg, Collaborative Institutional Training Initiative (CITI), Good Clinical Practice).

\section{Role of Infection Prevention Staff and Direct Care HCP}

\section{Recommendations.}

1. During all phases of incident management, infection prevention staff should:

a. Collaborate with and support the HE.

b. Continue to perform outbreak surveillance and effectively communicate this information to the HE.

c. Provide knowledge and skills regarding infection prevention practices.

2. A direct-care HCP should be able to do the following:

a. Recognize that clusters of patients or HCP with infection, or a single patient or HCP with a very unusual infection, may represent the start of an outbreak.

b. Report this to infection prevention and control staff.

c. Continue to perform standard infection prevention and control measures while awaiting further guidance from infection prevention and control.

3. The direct-care HCP designated to provide patient care during an outbreak setting should demonstrate competency in standard and special protocols to respond to and contain pathogens within the scope of practice.

Rationale. A facility's surveillance program must include protocols for direct care HCP to identify, isolate, and notify relevant authorities, as front line HCP often notice outbreaks in very early stages. ${ }^{12,25,41,69} \mathrm{HCP}$ should follow their organization's policies and procedures. Once a facility or emerging 
pathogen outbreak is identified, the direct-care HCP should continue to follow the facility's infection prevention and control and occupational health and safety policies and procedures, including interim guidance from infection prevention and facility leadership regarding specific measures to contain the outbreak. For certain pathogens, such as EVD, the facility should ensure additional training to create dedicated teams of HCP for provision of care within their scope of practice. ${ }^{70}$

The knowledge and skills required to plan for and respond to a facility or emerging pathogen outbreak fall within the infection prevention and control areas of responsibility. ${ }^{41,71}$ The infection preventionist (IP) applies surveillance definitions and methodologies and ensures timely communication with the HE. The core competencies of an IP include infection prevention and control activities and championing a safety culture within multidisciplinary incident management teams and clinical supportive staff. ${ }^{41,71}$ Infection prevention staff members are not expected to participate in direct patient care activities unless those activities are within the scope of their background and training. ${ }^{42}$

\section{Special Considerations for Resource-Limited Facilities and Special Patient Populations}

Certain populations and healthcare settings, such as pediatric patients, resource-limited facilities, and long-term-care facilities (LTCFs) may have unique challenges in preparing for and responding to infectious disease outbreaks. Below are setting and population-specific recommendations and resources.

\section{Resource-Limited Facilities}

\section{Recommendations.}

1. Resource-limited facilities should use an HVA to assess their capacity to respond to outbreaks, and mitigate deficiencies through identification and training of local experts, collaboration with established infection prevention and control programs, and consultation with HEs.

2. Resource-limited facilities should access local, state/ territorial/regional, and federal EMPs and services when developing their EMP.

3. Resource-limited facilities should develop JASs that combine and prioritize HIMT positions according to the facility's capabilities and needs.

4. The HE should participate in exercises/drills, which provide experience in incident management procedures and interaction with facility leaders and staff.

Rationale. Community and critical access hospitals and other healthcare facilities, such as long-term care facilities (LTCFs), face unique challenges when approaching incident management for infectious diseases outbreaks because of significant variability in available resources. During the preparedness stage, such facilities should conduct
HVAs/risk assessments to identify gaps, including potential for decreases in number of personnel due to illness and limitations due to the facility's location (eg, rural). Once resource gaps are identified, the facility should contact local hospitals or public health partners to assist in mitigating gaps.

Facilities can improve response plans though collaboration with other local facilities, ${ }^{4}$ partnership with a larger facility or network of hospitals with established infection prevention and control policies, and hiring a consultant HE. As resourcelimited facilities may not be equipped to handle all emerging pathogens, hospitals should work with state and public health departments to facilitate transfer of patients to the closest facility in their region with the appropriate level of care. Effective planning should lead to the preemptive establishment of emergency assistance agreements, including mutual aid agreements or memoranda of understanding among community and local facilities. ${ }^{32}$ Facilities should ensure a detailed understanding of supports and resources available through local/county, state/territorial/regional, and federal public health agencies that can be accessed if outbreak management resources need to be mobilized in an urgent situation. Assistance also may be available from state/territorial/regional emergency operations centers and state and federal response teams within NIMS, the National Disaster Medical System (NDMS), CDC, HHS biocontainment units, and the National Response Framework (NRF). ${ }^{13}$

Facilities should use HICS to manage threats or emergency incidents, including emerging pathogen outbreaks, and align their EMP with local EMS, fire and law enforcement, public and behavioral health facilities, other area or regional hospitals, and public or private organizations. ${ }^{10}$ The facility may need to develop modifications to HICS specifically to address limited resources. For smaller hospitals, most adaptations require combining job roles of the HIMT using JAS, which can be modified to blend positions to better fit hospitals that have fewer staff to respond in an incident, recognizing that some positions are more easily combined than others. Several resources provide instructions and sample worksheets to effectively combine and prioritize HIMT positions. ${ }^{6,14,72}$

Smaller hospitals or nonhospital healthcare facilities may contract with another facility or a specific individual to provide HE services. The HE will likely serve in the role of medicaltechnical specialist within the HICS structure. Community infectious diseases physicians who will act as medical-technical specialists to the IC may be challenged by lack of partners inside and outside the facility. They should prioritize developing relationships with facility staff and decision-makers inside the facility. This may be accomplished by pairing the $\mathrm{HE}$ with an administrative counterpart who is familiar with the facility and key personnel. If the HE is contracting with a facility, he/she should address his/her role in incident management and emergency response and negotiate for financial resources for training and leadership development, as well as 
provisions for remote assistance if the HE normally practices in other locations. Facilities should consider sending key staff, including HEs, for educational training to build personnel knowledge and expertise in outbreak response. The HE should have access to the facility's contacts that will provide operational assistance, to include the local health commissioner, chief of police, sheriff, local emergency management and safety officials the facility's legal counsel, and state/territorial/regional department of health contacts.

\section{Special Patient Populations}

\section{Recommendations.}

1. Facilities should be aware that pregnant women and immunocompromised individuals may have atypical presentations of illness that could lead to delayed diagnosis, or be at higher risk for severe complications or prolonged contagiousness, all of which may lead to greater potential for cross transmission to other patients, $\mathrm{HCP}$, and visitors.

2. The EOP should incorporate special considerations for pediatric patients:

a. Encouragement of parental/guardian involvement in the care and support of children, whether in person or through videoconferencing technology.

b. Safety considerations for parent(s)/guardian(s) to be at the bedside, including:

i. Whether the parent/guardian already has been exposed to the pathogen, or is considered immune (eg, measles).

ii. Whether the facility has the capacity to provide care for the parent/guardian if he or she becomes ill.

iii. If the parent/guardian has a condition that places them at increased risk (eg, pregnancy, immunocompromised).

iv. If the parent/guardian can don/doff appropriate PPE and follow infection prevention and control policies and procedures.

3. In staffing considerations, the facility should consider the following:

a. The added daily care and supervision tasks children require when parent(s)/guardian(s) cannot be involved.

b. The potential for increased liaising with public health departments in outbreaks involving school children, university students, childcare centers, and residential facilities.

Rationale. Outbreaks of infections that disproportionately affect pregnant women require special resources and preparedness plans, including coordination with adult and neonatal intensive care units and labor and delivery $\mathrm{HCP}^{73}$

Few evidence-based recommendations exist to inform policies and procedures around parental/guardian presence during outbreak situations. The American Academy of Pediatrics issued a clinical report based on experience during the 2014 EVD Outbreak, ${ }^{74}$ which reviews options, including minimizing visitors by utilizing electronic means of communication (eg, videophone, email) to allow the patient to interact with a larger sphere of family and friends. Planning for parental/guardian presence should occur prior to patient arrival, and should include input from the ethics committee (or equivalent) and child's life (or equivalent), in addition to physician, nursing, hospital administration, and infection prevention. Hospital staff must be aware of parental/guardian anxiety, and encourage frequent communication regarding the child's clinical condition and progress. $^{75}$ If parent(s)/guardian(s) are affected by the outbreak and hospitalized, videophone communication can provide an important link to children; however, the psychological impact to a child of seeing an ailing parent/ guardian should be weighed against the benefit of mutual support.

Notably, while this section focuses on pediatric patients, issues regarding family members/visitors at the bedside also arise for adult patients. The facility should plan for how it will handle family members and visitors of all patients, including adults, and include those plans in the EOP.

In an outbreak setting, staffing considerations must consider the added daily care and supervision tasks children require. ${ }^{76}$ As part of facility preparedness, facilities should consider the number of daily care activities that rely on parental/guardian presence. Depending on their age, many children rely on assistance with feeding, bathing, diaper changing, nose wiping, and other care, even when healthy. Parent(s)/guardian(s) routinely participate in these activities for their hospitalized children, and when parent(s)/guardian(s) are not available to perform these tasks, they fall to the nursing staff.

Because of the close quarters, dormitory living, and frequent contacts, outbreaks of contagious pathogens occur in universities, childcare centers, schools, and residential care facilities. Ongoing outbreaks at the time of a school break can lead to widespread expansion as students bring the infection to their homes and communities. To contain spread, the facility may need to provide increased communication/liaising with relevant local and state/territorial/regional health departments. ${ }^{76}$

\section{Long-Term-Care Facilities}

\section{Recommendations.}

1. During preparedness and response to an emerging pathogen outbreak, the acute-care hospital should do the following:

a. Develop collaborative protocols and conduct preplanning exercises/drills to facilitate interaction.

b. Ensure clear and timely communication with LTCFs and EMS transport.

2. This document does not provide recommendations for adapting acute-care policies to other settings, such as longterm-care (LTC) and postacute-care facilities, due to the 
lack of literature on the topic; however, these facilities should review the resources listed below to help their preparedness and response efforts for infectious diseases outbreaks.

Rationale. LTCFs are a critical component of the healthcare system. Recent focus on the role of LTCFs in disaster preparedness and response has led to numerous resources supporting the integration of these facilities into incident management efforts:

a. CDC planning resources by setting: long-term, acute, and chronic care. ${ }^{77}$

b. The California Association of Health Facilities Disaster Preparedness Program: resources and tools to assist LTCFs with disaster planning and provide standardized methods specifically intended for LTCFs to respond to new incidents. ${ }^{78}$

c. Nursing Home Incident Command System (NHICS): Appendix I: Resources and References. ${ }^{72}$

d. HICS for Small Hospitals ${ }^{14}$ : provides guides intended for small and rural hospitals that also face issues with limited personnel and other resources. Technical support and facilitation, from a federal or local partner or the private sector may improve communication and information sharing. ${ }^{79}$

e. Transfer forms

i. CDC Prevention Tool Kits ${ }^{80}$

ii. Registries used to monitor spread of multidrug-resistant organisms (MDROs) and improve communication with interfacility transfer at the state/territorial/regional levels. ${ }^{81}$

During an emerging pathogen outbreak, clear, effective, and timely communication between the acute-care hospital and LTCF is essential to support infection prevention and control efforts, assist in antibiotic stewardship, and provide surveillance in real time. ${ }^{82}$ Establishing communications channels between an acute-care hospital and LTCF helps identify barriers/gaps prior to an outbreak. The infection prevention and control team at the acute-care hospital should identify a designated contact person, infection preventionist, or HE for all transfers to an LTCF.

After stabilization and supportive care in an acute-care setting is complete, patients with chronic disabilities or rehabilitation needs may be transferred to an LTCF. The extent and type of information relayed from the facility to the LTCF will vary depending on the type of outbreak and the resources needed to prevent transmission and maintain HCP and patient safety. Transfer of information should occur prior to the patient arriving in an LTCF so that appropriate accommodation (eg, private room, necessary contact supplies) can be arranged. Essential information should be transmitted both verbally (eg, RN/MD to RN/MD/LPN) and either electronically through a dedicated computer system, or through a standardized form. ${ }^{5,80}$
Essential communication components should include, but are not limited to:

a. Need for isolation

b. Type of isolation (eg, contact, droplet)

c. Duration of isolation, if known

d. Type of infection

e. Immunization status

f. Current symptoms (eg, incontinence of stool, wounds)

g. Need for additional personnel to provide care

h. Devices (eg, central line) information including time of insertion and plan for management

i. Plan for anti-infective therapy administration and infectious disease follow-up

j. Plan for scheduled monitoring of any predetermined clinical finding and/or laboratory values specific to the anti-infective therapy and reporting those to the physicians managing the infection

$\mathrm{k}$. Environmental cleaning recommendations

LTCFs should be encouraged to ask questions to have a clear understanding of all components listed above or any details regarding a patient's care prior to transfer.

\section{ACKNOWLEDGMENTS}

Financial support: This manuscript was supported in part by the SHEA Research Network. This guidance was written as part of the SHEA/CDC Outbreak Response Training Program (ORTP contract no. 200-2016-89263).

Potential conflicts of interest: The following disclosures reflect what has been reported to SHEA. To provide thorough transparency, SHEA requires full disclosure of all relationships, regardless of relevancy to the guideline topic. Evaluation of such relationships as potential conflicts of interest is determined by a review process which includes assessment by the SHEA Guidelines Chair, the SHEA Conflict of Interest Committee, and may include the Board of Trustees and Editor of Infection Control and Hospital Epidemiology. The assessment of disclosed relationships for possible conflict of interest is based on the relative weight of the financial relationship (ie, monetary amount) and the relevance of the relationship (ie, the degree to which an association might reasonably be interpreted by an independent observer as related to the topic or recommendation of consideration). The reader of these guidelines should be mindful of this when the list of disclosures is reviewed. B.L.J. reports research grants/contracts with Canadian Institute Health Research (CIHR), Capital District Research Fund, Canadian HIV Trials Network/Canadian Cohort of Slow Progressors (coinvestigator), Capital District Health Authority/Frailty in HIV Infection (principal investigator), Pfizer (co-investigator HIV drug contract) and Nova Scotia Health Research Fund and serves as the SHEA representative for the IDSA Influenza Management Guideline update, the Co-Chair of the Public Health Agency of Canada (PHAC) Expert Working Group Infection Prevention and Control Guidelines, and member of the working group for guidelines for the HCP infected with a blood borne pathogens. J.G.C. serves in an advisory/consultant Role with the Infection Prevention Consulting of Oregon, LLC, and reports research grants/contracts with AHRQ, the Community Central Line Infection Prevention (CCLIP) Trial (site PI). S.B. reports research grants/contracts with Rempex Pharmaceuticals, INC and organizational relationships with Rempex, NIAID, and serves on the Rempex UIC Department of Medicine, Clinical Trials $(>\$ 25,000)$, NIAID/UIC Department of Medicine, Clinical Trials $(>\$ 25,000)$ and is a committee member of the IDSA Clinical Affairs Committee. V.D. works as a consultant for SHEA supporting the Guidelines Committee and SHEA Research Network and as a subcontractor for the ORTP (CDC contract no. 200-2016-89263). K.E. reports research grants/contracts with the NIH, organizational 
relationships with the NIH and Boston Scientific. C.L. reports research grants/ contracts with Sage Products, LLC, and serves on the Providence Health Care development of a chlorhexidine gluconate QAC and SMR PCR $(\$ 10,000)$. L.O.Z. reports an advisory/consultant role with Astellas, Merck, Cidara, Xenex; honoraria from T2 Biosystems, Pfizer; research grants/contracts with Astellas; organizational relationships with T2 Biosystems, Pfizer, Scynexis; and serves on the IDSA guidelines task force and as Associate Editor JAC. P.K.P. reports research grants/contracts with AHRQ and organizational relationships with CDC/HERT. K.J.P. reports research grants/contracts with NIAID; organizational relationships with CDC, and serves on the IDSA SPGC. E.S.S. reports research grants/contracts with NIAID; organizational relationships with MGH-MIT Grand Challenge; and serves as a member of the IDSA Antimicrobial Resistance Committee and Board member of the Massachusetts Infectious Diseases Society. R.S. reports research grants/contracts with Parkview Health; organizational relationships with Geo-epidemiology and Molecular Characterization of Hepatitis C in Northeastern Indiana A Retrospective Study; and serves on the Board of Directors of Ohio State Medical Association. All other authors report no conflicts of interest relevant to this article.

Address correspondence to David B. Banach, MD, MPH, MS, University of Connecticut Health Center, 263 Farmington Ave, Farmington, CT 06030 (dbanach@uchc.edu).

SUPPLEMENTARY MATERIAL

To view supplementary material for this article, please visit https://doi.org/10.1017/ice.2017.212

\section{REFERENCES}

1. Institute of Medicine (IOM). Emerging infections: microbial threats to health in the United States. National Academeies Press website. www.nap.edu/read/2008/chapter/1. Published 1992. Accessed September 28, 2017.

2. Kaye KS, Anderson DJ, Cook E, Huang SS, Siegel JD, Zuckerman $\mathrm{JM}$, et al. Guidance for infection prevention and healthcare epidemiology programs: healthcare epidemiologist skills and competencies. Infect Control Hosp Epidemiol 2015;36: 369-380.

3. The SHEA handbook for SHEA-sponsored guidelines and expert guidance documents. Society for Healthcare Epidemiology of America (SHEA) website. www.shea-online.org/index.php/ practice-resources. Published 2015. Accessed January 2017.

4. Hospital Preparedness Program (HPP), National Incident Management System (NIMS) Implementation for Healthcare Organizations Guidance. Office of the Assistant Secretary for Preparedness and Response (ASPR) website. www.phe.gov/Preparedness/ planning/hpp/reports/Documents/nims-implementation-guidejan2015.pdf. Published 2015. Accessed January 2017.

5. Federal Emergency Management Agency (FEMA), Emergency Management Institute (EMI). National Incident Management System (NIMS) website. https://training.fema.gov/nims/. Published 2015. Accessed November 2016.

6. Emergency Medical Services Authority (EMSA). Hospital Incident Command System (HICS) Guidebook, 5th ed., website. Published May 2015. Accessed November 2016.

7. Stanford Health Care. The hospital incident command system: a guide for hospital personnel. YouTube website. www.youtube.com/ watch?v=14SGKLZM5c0\&feature=youtu.be. Published 2015. Accessed January 2017.
8. Emergency support function annexes: introduction. Federal Emergency Management Agency website. www.fema.gov/medialibrary-data/20130726-1825-25045-0604/emergency_support_ function_annexes_introduction_2008_.pdf. Published 2008. Accessed January 2017.

9. 2017-2022 Hospital preparedness program performance measures implementation guidance. Office of the Assistant Secretary for Preparedness and Response website. www.phe.gov/Preparedness/ planning/hpp/reports/Documents/hpp-pmi-guidance-2017.pdf. Published 2017. Accessed May 2017.

10. Healthcare preparedness capabilities: National guidance for healthcare system preparedness. Office of the Assistant Secretary for Preparedness and Response website. www.phe.gov/ preparedness/planning/hpp/reports/documents/capabilities.pdf. Published 2012. Accessed November 2016.

11. NIMS Appendix B: Incident command system. Federal Emergency Management Agency website. www.fema.gov/pdf/emergency/ nims/NIMS_AppendixB.pdf. Published 2008. Accessed November 2016.

12. Healthcare Organization (HCO) Emergency Operations Plan (EOP). Office of the Assistant Secretary for Preparedness and Response website. www.phe.gov/Preparedness/planning/mscc/ handbook/chapter2/Pages/hcoemergen.aspx. Published November 2012. Accessed October 10, 2017.

13. Hospital Incident Command System (HICS). Emergency Medical Services Authority website. www.emsa.ca.gov/disaster_medical_ services_division_hospital_incident_command_system_resources. Published 2014. Accessed November 2016.

14. Hospital Incident Command System (HICS) for small hospitals. Association of Healthcare Emergency Preparedness Professionals (AHEPP) website. https://ahepp.site-ym.com/?page=Incident Command. Published 2014. Accessed November 2016.

15. NIMS Training Program website. Federal Emergency Management Agency website. www.fema.gov/training-0. Published 2016. Accessed 2017 February.

16. What is the relationship between an Emergency Management Program (EMP) and an Emergency Operations Plan (EOP)? California Hospital Association (CHA) website. www.calhospitalprepare.org/ post/what-relationship-between-emergency-management-programemp-and-emergency-operations-plan-eop-0. Published 2015. Accessed May 2017.

17. CDC, HHS, Oak Ridge Institute for Science and Education (ORISE). Hospital All-Hazards Self-Assessment (HAH). Centers for Disease Control and Prevention Healthcare Preparedness Activity (CDC-HPA) website. www.cdc.gov/phpr/readiness/ healthcare/documents/hah_508_compliant_final.pdf. Published 2012. Accessed November 2016.

18. Emergency management standards supporting collaboration planning. The Joint Commission website. www.jointcommission. org/assets/1/6/EM_Stds_Collaboration_2016.pdf. Published 2016. Accessed November 2016.

19. Hospital preparedness planning: core capabilities. Centers for Disease Control and Prevention websites. www.cdc.gov/phpr/ healthcare/documents/dsns-hah_portfolio.final.pdf and www. cdc.gov/infectioncontrol/index.html. Published 2010. Accessed November 2016.

20. National Center for Immunication and Respiratory Diseases (NCIRD). Prevention strategies for seasonal influenza in healthcare settings. Centers for Disease Control and Prevention website. 
www.cdc.gov/flu/professionals/infectioncontrol/healthcaresettings. htm. Published 2016. Accessed November 2016.

21. NCIRD. Pandemic influenza. Centers for Disease Control and Prevention website. www.cdc.gov/flu/pandemic-resources/. Published 2016. Accessed November 2016.

22. CDC, NCIRD. Updated norovirus outbreak management and disease prevention guidelines. MMWR Recomm Rep 2011; 60:1-18.

23. National Center for Emerging and Zoonotic Infectious Diseases (NCEZID). Guidance for control of carbapenem-resistant Enterobacteriaceae (CRE) tool kit. Centers for Disease Control and Prevention website. www.cdc.gov/hai/organisms/cre/ cre-toolkit/index.html. Published 2015. Accessed November 2016.

24. Public health emergency response guide for state, local, and tribal public health directors. Centers for Disease Control and Prevention website. https://emergency.cdc.gov/planning/pdf/cdcresponseguide. pdf. Published 2011. Accessed November 2016

25. National Association of County and City Health Officials (NACCHO). Infectious Disease Emergency Response (IDER) tool kit. San Francisco Bay Area Advanced Practice Center (APC) website. http://toolbox.naccho.org/pages/tool-view.html?id=2190 APC project retired 2017. NACCHO Project Public Health Ready for additional tools: https://www.naccho.org/programs/ public-health-preparedness/pphr. Published 2011. Accessed November 2016.

26. Bartlett JG. Planning for avian influenza. Ann Intern Med 2006;145:141-144.

27. Nhan C, Laprise R, Douville-Fradet M, Macdonald ME, Quach C. Coordination and resource-related difficulties encountered by Quebec's public health specialists and infectious diseases/medical microbiologists in the management of $\mathrm{A}(\mathrm{H} 1 \mathrm{~N} 1)$ - a mixedmethod, exploratory survey. BMC Public Health 2012;12:115.

28. McCullers JA. Preparing for the next influenza pandemic. Pediatr Infect Dis J 2008;27:S57-9.

29. Biological and chemical terrorism: strategic plan for preparedness and response. Recommendations of the CDC Strategic Planning Workgroup. MMWR Recomm Rep 2000;49:1-14.

30. Sandman P, Lanard J. Crisis Communication I: How bad is it? How sure are you? Centers for Disease Control and Prevention website. www.cdc.gov/nceh/tracking/conf04/pdfs/thu/ses4A/ j_lanard.pdf. Published 2004. Accessed November 2016.

31. Office of Public Health Preparedness and Response (OPHPR). Crisis \& Emergency Risk Communication (CERC). Centers for Disease Control and Prevention website. http://emergency.cdc. gov/cerc/index.asp. Published 2016. Accessed November 2016.

32. Hospitals and community emergency response: What you need to know. Occupational Safety and Health Administration (OSHA) website. www.osha.gov/Publications/OSHA3152/3152hospitals.pdf. Published 2008. Accessed November 2016.

33. Requirements for emergency management oversight: Joint Commission perspectives. The Joint Commission website. www. jointcommission.org/assets/1/18/JCP0713_Emergency_Mgmt_ Oversight.pdf. Published July 2013. Accessed November 2016.

34. Selected federal legal authorities pertinent to public health emergencies. Centers for Disease Control and Prevention website. www.cdc.gov/phlp/docs/ph-emergencies.pdf. Published 2014. Accessed November 2016.

35. Emergency Medical Treatment and Labor Act (EMTALA): requirements and implications related to Ebola virus disease.
Centers for Medicare and Medicaid Services website. www.cms. gov/Medicare/Provider-Enrollment-and-Certification/SurveyCertificationGenInfo/Policy-and-Memos-to-States-and-RegionsItems/Survey-and-Cert-Letter-15-10.html. Published 2015. Accessed November 2016.

36. Medicare and Medicaid programs: emergency preparedness requirements for Medicare and Medicaid participating providers and suppliers. Federal Register website. www.federalregister.gov/ documents/2016/09/16/2016-21404/medicare-and-medicaidprograms-emergency-preparedness-requirements-for-medicareand-medicaid and Centers for Medicare and Medicaid Services website. www.cms.gov/Medicare/Provider-Enrollment-and-Certi fication/SurveyCertEmergPrep/Emergency-Prep-Rule.html. Published 2016. Accessed November 2016.

37. Emergency preparedness requirements for Medicare and Medicaid participating providers and suppliers: final rule. Centers for Medicare and Medicaid Services website. www.cms.gov/Medicare/ Provider-Enrollment-and-Certification/SurveyCertEmergPrep/ Emergency-Prep-Rule.html. Published 2016. Accessed November 2016.

38. Technical resources, assistance center, and information exchange (TRACIE). Office of the Assistant Secretary for Preparedness and Response website. https://asprtracie.hhs.gov/. Published 2015. Accessed January 2017.

39. Safely and effectively managing the infectious Ebola patient. The Joint Commission website. www.jointcommission.org/ joint_commission_standards_safely_and_effectively_managing the_infectious_ebola_patient/. Published 2014. Accessed November 2016.

40. Institute of Medicine. Guidance for establishing crisis standards of care for use in disaster situations: A letter report. National Academies Press website. www.nap.edu/read/12749/chapter/1\#ii. Published 2009. Accessed November 2016.

41. Bryant KA, Harris AD, Gould CV, et al. Necessary infrastructure of infection prevention and healthcare epidemiology programs: a review. Infect Control Hosp Epidemiol 2016;37:371-380.

42. Rebmann T. Assessing hospital emergency management plans: a guide for infection preventionists. Am J Infect Control 2009; 37:708-14.e4.

43. Emergency management program checklist. California Hospital Association website. www.calhospitalprepare.org/sites/main/files/ file-attachments/emp_checklist_v080311.doc. Published August 3, 2011. Accessed November 2016.

44. Pandemic influenza planning checklist 2015. Centers for Disease Control and Prevention website. www.cdc.gov/flu/pandemic-resources/pdf/hospitalchecklist.pdf. Published 2015. Accessed October 2017.

45. Bellevue Hospital Center. Ebola virus disease (EVD) incident response guide. National Ebola Training and Education Center website. https://netec.org/wp-content/uploads/2017/03/BellevueEVD-IRG.pdf. Published 2016. Accessed November 2016.

46. Interim guidance for a health response to certain novel or targeted multidrug-resistant organisms (MDROs). Centers for Disease Control and Prevention websites. www.cdc.gov/hai/outbreaks/ docs/health-response-contain-mdro.pdf and www.cdc.gov/infection control/index.html. Published 2017. Accessed March 2017.

47. Markiewicz M, Bevc CA, Hegle J, Horney JA, Davies M, MacDonald PD. Linking public health agencies and hospitals for improved emergency preparedness: North Carolina's public health epidemiologist program. BMC Public Health 2012;12:141. 
48. National Center for Immunization and Respiratory Diseases (NCIRD). For clinicians: Evaluating and managing patients exposed to birds infected with avian influenza viruses of public health concern. Centers for Disease Control and Prevention website. www.cdc.gov/flu/avianflu/clinicians-evaluating-patients. htm. Published 2016. Accessed November 2016.

49. Tools for infectious diseases emergencies. San Francisco Bay Area Advanced Practice Center website. Webpage retired 2017. IDER reference site: http://toolbox.naccho.org/pages/tool-view.html? id=2190 Alternate tools on San Francisco Department of Public Health: http://www.sfcdcp.org/exercises.html. Published 2012. Accessed November 2016.

50. Siegel JD, Rhinehart E, Jackson M, Chiarello L, HICPAC. 2007 Guideline for isolation precautions: preventing transmission of infectious agents in health care settings. Am J Infect Control 2007;35:S65-S164.

51. 2015 Update investigation and control of vancomycin-resistant Staphylococcus aureus (VRSA). Centers for Disease Control and Prevention website. www.cdc.gov/hai/pdfs/vrsa-investigationguide-05_12_2015.pdf and www.cdc.gov/infectioncontrol/index. html. Published 2015. Accessed November 2016.

52. Garnacho-Montero J, Dimopoulos G, Poulakou G, et al. Task force on management and prevention of Acinetobacter baumannii infections in the ICU. Intensive Care Med 2015;41:2057-2075.

53. Sandrock CE. Severe febrile respiratory illnesses as a cause of mass critical care. Respir Care 2008;53:40-53; discussion, 7.

54. Puro V, Fusco FM, Lanini S, Nisii C, Ippolito G. Risk management of febrile respiratory illness in emergency departments. New Microbiol 2008;31:165-173.

55. Public health and information sharing toolkit. Association of State and Territorial Health Officials (ASTHO) website. www. astho.org/Programs/Preparedness/Public-Health-Emergency-Law/ Public-Health-and-Information-Sharing-Toolkit/. Published 2012. Accessed November 2016.

56. Brouqui P. Facing highly infectious diseases: new trends and current concepts. Clin Microbiol Infect 2009;15:700-705.

57. Brett-Major DM, Jacob ST, Jacquerioz FA, et al. Being ready to treat Ebola virus disease patients. Am J Trop Med Hyg 2015;92:233-237.

58. Tompkins BM, Kerchberger JP. Special article: personal protective equipment for care of pandemic influenza patients: a training workshop for the powered air purifying respirator. Anesth Analg 2010;111:933-945.

59. Srinivasan A, McDonald LC, Jernigan D, et al. Foundations of the severe acute respiratory syndrome preparedness and response plan for healthcare facilities. Infect Control Hosp Epidemiol 2004;25:1020-1025.

60. Hospital $2009 \mathrm{H} 1 \mathrm{~N} 1$ readiness review checklist. Centers for Disease Control and Prevention website. www.cdc.gov/phpr/ readiness/healthcare/documents/hospital_2009h1n1_checklist.pdf and www.cdc.gov/infectioncontrol/index.html. Published 2009. Accessed November 2016.

61. NCIRD. Interim infection prevention and control recommendations for hospitalized patients with Middle East respiratory syndrome coronavirus (MERS-CoV). Centers for Disease Control and Prevention website. www.cdc.gov/coronavirus/mers/ infection-prevention-control.html. Published 2015. Accessed November 2016.

62. Tomizuka T, Kanatani Y, Kawahara K. Insufficient preparedness of primary care practices for pandemic influenza and the effect of a preparedness plan in Japan: a prefecture-wide crosssectional study. BMC Fam Pract 2013;14:174.

63. Fischer WA, Weber DJ, Wohl DA. Personal protective equipment: protecting health care providers in an Ebola outbreak. Clin Ther 2015;37:2402-2410.

64. Gamage B, Moore D, Copes R, Yassi A, Bryce E, Group BIRPS. Protecting health care workers from SARS and other respiratory pathogens: a review of the infection control literature. Am J Infect Control 2005;33:114-121.

65. Teleman MD, Boudville IC, Heng BH, Zhu D, Leo YS. Factors associated with transmission of severe acute respiratory syndrome among health-care workers in Singapore. Epidemiol Infect 2004;132:797-803.

66. Sprecher AG, Caluwaerts A, Draper M, et al. personal protective equipment for filovirus epidemics: a call for better evidence. J Infect Dis 2015;212(Suppl 2):S98-S100.

67. DeGennaro M, Feistritzer N, Gartland B, Sprouse E. Ebola preparedness protocols. Emory Healthcare website. www. emoryhealthcare.org/ebola-protocol/ehc-message.html. Published 2016. Accessed November 2016.

68. Lane HC, Marston HD, Fauci AS. Conducting clinical trials in outbreak settings: points to consider. Clin Trials 2016;13: 92-95.

69. National Center for Emerging and Zoonotic Infectious Diseases (NCEZID). Healthcare-associated infection (HAI) outbreak investigation tool kit. Centers for Disease Control and Prevention website. www.cdc.gov/hai/outbreaks/outbreaktoolkit.html and www.cdc.gov/infectioncontrol/index.html. Published 2014. Accessed November 2016.

70. NCEZID. Infection prevention and control recommendations for hospitalized patients under investigation (PUIs) for Ebola virus disease in U.S. hospitals. Centers for Disease Control and Prevention website. www.cdc.gov/vhf/ebola/healthcare-us/hospitals/ infection-control.html. Published 2015. Accessed November 2016.

71. Murphy DM, Hanchett M, Olmsted RN, et al. Competency in infection prevention: a conceptual approach to guide current and future practice. Am J Infect Control 2012;40:296-303.

72. Disaster Preparedness Program (DPP) Nursing Home Incident Command System. California Association of Health Facilities (CAHF) website. www.cahfdisasterprep.com/nhics. Published 2011. Accessed November 2016.

73. Beigi RH, Hodges J, Baldisseri M, English D, Committee M-WHE. Clinical review: considerations for the triage of maternity care during an influenza pandemic-one institution's approach. Crit Care 2010;14:225.

74. Davies HD, Byington CL, Diseases COI. Parental presence during treatment of Ebola or other highly consequential infection. Pediatrics 2016:138.

75. Chen WK, Wu HD, Lin CC, Cheng YC. Emergency department response to SARS, Taiwan. Emerg Infect Dis 2005;11:1067-1073.

76. Mehrotra P, Shane AL, Milstone AM. Family-centered care and high-consequence pathogens: thinking outside the room. JAMA Pediatr 2015;169:985-986.

77. Office of Public Health Preparedness and Response (OPHPR). Planning resources by setting: long-term, acute, and chronic care. Centers for Disease Control and Prevention website. www.cdc. gov/phpr/healthcare/planning2.htm. Published 2016. Accessed November 2016. 
78. California Department of Public Health (CDPH). California Association of Health Facilities Disaster Preparedness Program (CAHF-DPP). California Association of Health Facilities (CAHF) website. www.cahfdisasterprep.com/. Published 2006. Accessed November 2016.

79. Tupper JB, Gray CE, Pearson KB, Coburn AF. Safety of rural nursing home-to-emergency department transfers: improving communication and patient information sharing across settings. J Healthcare Qual 2015;37:55-65.

80. NCEZID. Prevention tool kits: example infection control transfer forms. Centers for Disease Control and Prevention website. www.cdc. gov/hai/prevent/prevention_tools.html and www.cdc.gov/infection control/index.html. Published 2015. Accessed November 2016.

81. Trick WE, Lin MY, Cheng-Leidig R, et al. Electronic public health registry of extensively drug-resistant organisms, Illinois, USA. Emerg Infect Dis 2015;21(10):1725-1732.

82. MacDonald RD, Farr B, Neill M, et al. An emergency medical services transfer authorization center in response to the Toronto severe acute respiratory syndrome outbreak. Prehosp Emergency Care 2004;8:223-231.

\section{APPENDIX 1. NEEDS ASSESSMENT}

\section{METHODS}

A needs assessment survey, disseminated online via RealMagnet software (Bethesda, MD), was sent to US SHEA Research Network (SRN) members in July 2016 with 3 weeks for completion. It included 25 questions regarding hospital policies, current practices, management of specific infections and outbreaks, and resources. Basic information about respondents and hospital affiliation was linked in aggregate to survey findings.

While this survey represented a small sample of diverse US hospitals, there is likely a bias toward hospitals that prioritize infection prevention because they are already SRN members and chose to participate; therefore, it is possible that the represented hospitals are better trained with more infection prevention practices in place than other US hospitals.

\section{RESULTS}

Of the 87 eligible members (who serve as HEs or infectious diseases specialists at their institutions), 49 (56\%) completed the survey.

\section{Respondent and Hospital Characteristics}

Of the 49 respondents, 43 have the following, nonexclusive primary hospital roles: 37 (86\%) epidemiologist, 28 (65\%) infection control committee chair, $26(60 \%)$ patient care, $23(53 \%)$, teaching/education, 22 (51\%) clinical research, 10 (23\%) administration, 4 (9\%) infection preventionists, 4 (9\%) public health, 2 (5\%) antibiotic stewardship, 1 (2\%) basic research, $1(2 \%)$ clinical microbiology, and $1(2 \%)$ quality and safety chair.

The hospitals represented are diverse. Of the 46 for which information is available: 27 (59\%) academic centers, 8 (17\%) community hospitals with academic affiliation, 4 (9\%) community nonacademic hospitals, 2 (4\%) Veterans Affairs hospitals, 2 (4\%) children's hospitals, 2 (4\%) nonmilitary federal hospitals, 2 (4\%) acute-care adult and pediatrics, and 1 $(2 \%)$ of each of the following: rehabilitation, home care tertiary, tertiary, public, teaching, and outpatient surgical. The hospitals ranged in size from $<100$ licensed beds to $>1,000$ licensed beds. Of the 44 hospitals with information available, 2 (5\%) have <100 beds, 10 (23\%) have 101-300 beds, 14 (32\%) have $301-500$ beds, 4 (9\%) have 501-700 beds, 5 (11\%) have 701-900 beds, 5 (11\%) have >1,000 beds.

\section{Staff Responsibilities and Knowledge}

Figure 3 displays the frequency of respondents' infection prevention-related responsibilities. The survey assessed the hospital's clinical and nonclinical staff's knowledge of CDC "Ebola Assessment Domains for Infection Prevention and Management." For each domain, respondents indicated whether hospital staff relevant to that domain fit into 1 of 4 categories: "need more information," "somewhat knowledgeable," "very knowledgeable," or "don't know."

\section{Incident Command}

All 49 respondents indicated familiarity with their institution's HICS. Twenty-eight (57\%) were familiar before the US Ebola experience and 21 (43\%) became familiar during the US Ebola alert. Respondents were asked what role they serve in the HICS; of the 48 respondents, 46 (96\%) respondents serve as the medical technical specialist, $3(6 \%)$ as the incident commander, $3(6 \%)$ as the planning chief, and $1(2 \%)$ as the logistics chief. Forty (82\%) hospitals indicated that the emerging infection preparedness infrastructure was incorporated into the HICS, while $3(6 \%)$ reported that it was not and $6(12 \%)$ did not know.

\section{Outbreak Simulations}

Forty-four hospitals (90\%) reported the use of simulation training. Departments and/or groups included were the emergency department $(n=44 ; 100 \%)$, laboratory management $(n=37 ; 84 \%)$, hospital security $(n=37 ; 84 \%)$, intensive care unit personnel $(\mathrm{n}=36 ; 82 \%)$, and environmental services $(\mathrm{n}=35 ; 80 \%)$. The departments/groups least involved were outpatient areas $(\mathrm{n}=12 ; 27 \%)$, and medical/surgical ward personnel $(n=13 ; 30 \%)$.

\section{Specific Emerging Infections}

Respondents were asked about 7 infectious diseases and whether specific policies and procedures exist, are simulated, implemented, and HICS activated for management and treatment (Table 4). Of 48 responding hospitals, common policies included 48 Ebola (100\%), 44 pandemic influenza (92\%), and 40 CRE (83\%). Among hospitals with policies, 43 hospitals (90\%) have simulated Ebola, 28 hospitals (64\%) have simulated pandemic influenza, and $14(40 \%)$ have simulated MERS-CoV. Twenty-nine (60\%) hospitals have activated their 


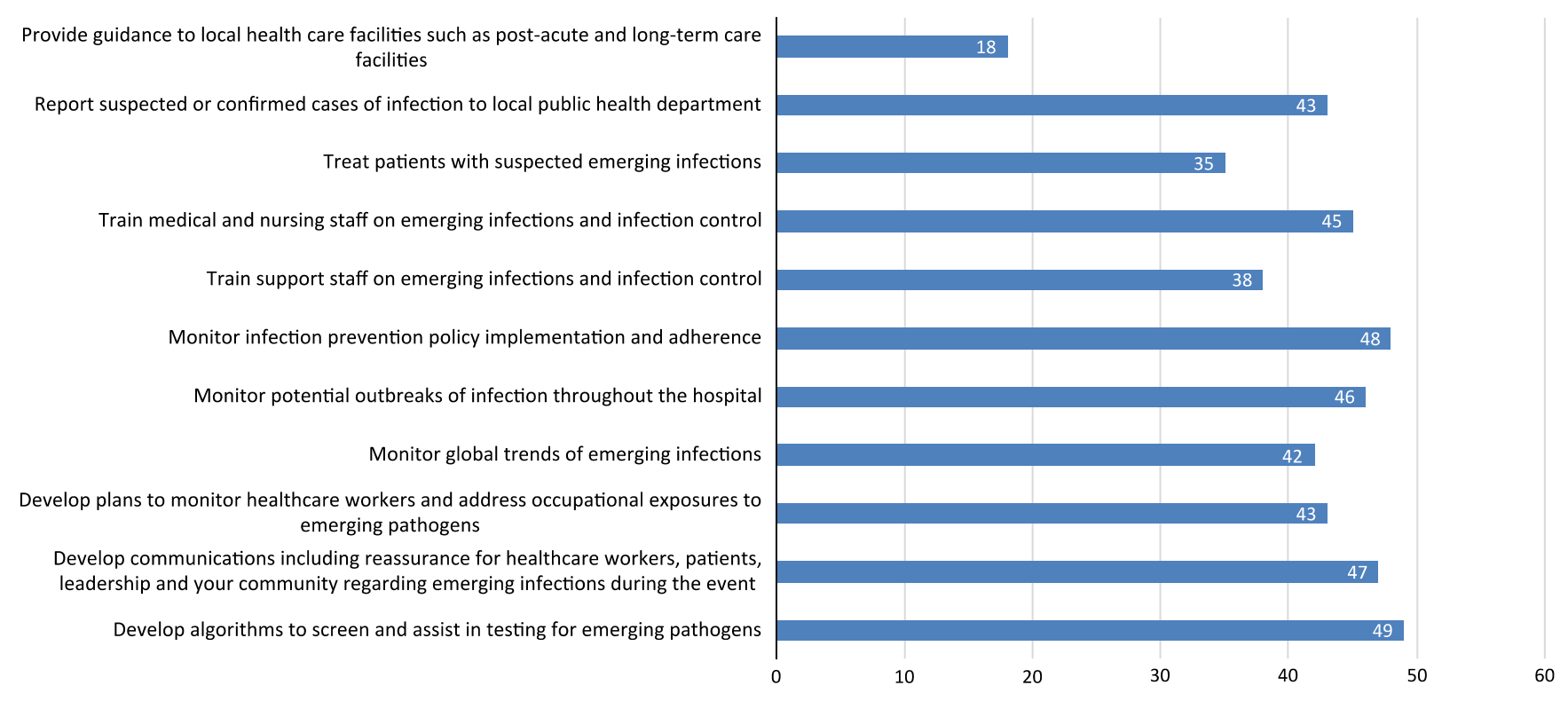

FIGURE 3. Emerging infection preparedness responsibilities.

тавцE 4. Hospital Policies, Simulations, Suspect/Treated Cases and HICS Activation for Specific Emerging Infections

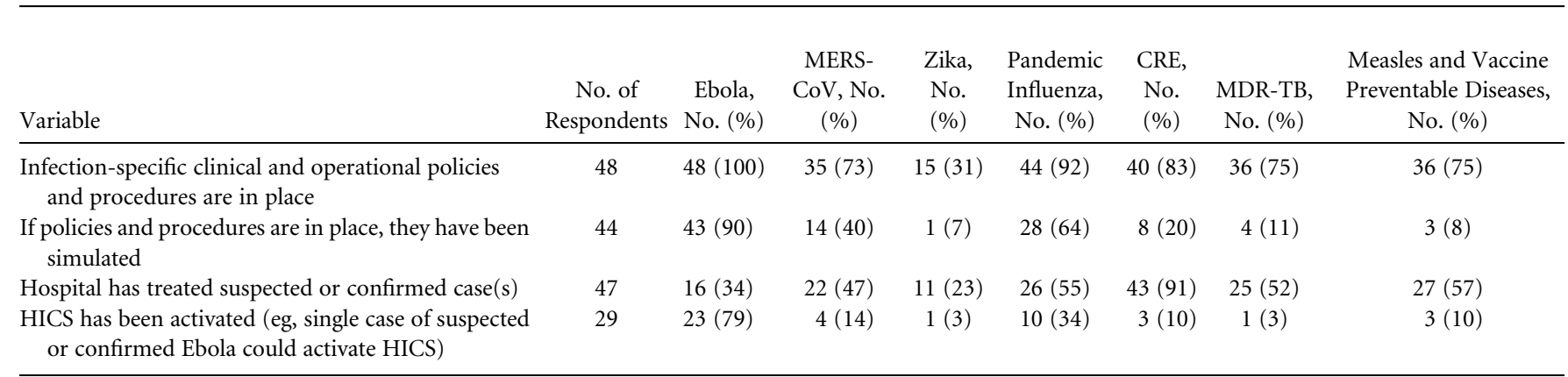

NOTE. HICS, hospital incident command system; MERS-CoV, Middle East respiratory syndrome-coronavirus; CRE, carbapenem-resistant Enterobacteriaceae; MDR-TB, multidrug-resistant tuberculosis.

HICS, primarily for Ebola $(\mathrm{n}=23 ; 79 \%)$ and pandemic influenza $(n=10 ; 34 \%)$. Of these, only 16 hospitals have treated suspected or confirmed cases of Ebola.

\section{Training}

Respondents were asked about information sources for emerging infections. All respondents utilize CDC guidance. Other trusted resources include: state and local health departments $(n=45 ; 92 \%)$, SHEA $(n=40 ; 82 \%)$, the World Health Organization $(n=40 ; 82 \%)$, and the Infectious Diseases Society of America $(n=38 ; 78 \%)$.

Staff training varies among hospitals. Overall, 36 hospitals (73\%) train staff members during an outbreak or epidemic. Otherwise, training varies by department $(n=22 ; 45 \%)$, or occurs annually $(\mathrm{n}=22 ; 45 \%)$. Interestingly, infectious diseases education only happens upon hire in 19 hospitals (39\%).

The most common types of staff education tools that respondents requested include clinical vignettes and table top exercises $(\mathrm{n}=39 ; 80 \%)$, checklists $(\mathrm{n}=32 ; 65 \%)$, and online or in-person simulations $(n=31 ; 63 \%)$. Less than half of respondents requested research articles $(n=6 ; 12 \%)$ and fact sheets $(n=22 ; 45 \%)$.

\section{Communications}

When hospitals communicate infection prevention information to patients and the public, several strategies are used including written education materials in patient waiting areas $(\mathrm{n}=41 ; 84 \%)$, hospital websites $(\mathrm{n}=40 ; 82 \%)$, and as-needed direct communications between clinical staff and patients $(\mathrm{n}=39 ; 80 \%)$. Email, verbal education in patient waiting areas, and social media were used by less than half of responding hospitals.

Of 49 responding hospitals, 45 (92\%) reported a communication strategy with state and local health departments. Many hospitals $(\mathrm{n}=39 ; 80 \%)$ have an established communication procedure with other regional healthcare facilities for serious 
emerging infections. Some hospitals use outside communication facilitators during an outbreak or epidemic including: the state health department $(\mathrm{n}=40 ; 82 \%)$, local health department $(\mathrm{n}=37 ; 76 \%)$, local hospital associations $(\mathrm{n}=16 ; 33 \%)$, and local Association for Professionals in Infection Control and Epidemiology (APIC) chapter $(\mathrm{n}=11 ; 22 \%)$. Of 48 responding hospitals, $40(83 \%)$ reported a system in place to coordinate care with other facilities (eg, Ebola Treatment Centers).

Of the 49 responding hospitals, $43(88 \%)$ reported an established media communication strategy for suspected cases of serious emerging infections or infection control practices. Of the 48 responding hospitals, 45 (94\%) have trained public relations staff. Other trained staff include hospital administrators $(n=28 ; 58 \%)$, healthcare epidemiologists $(n=21$; $44 \%)$, medical directors of infection prevention $(n=16 ; 33 \%)$, and infectious diseases physicians $(\mathrm{n}=8 ; 17 \%)$.

Of the 49 responding hospitals, 15 (31\%) have an established group who meet regularly and can rapidly develop a regional emerging infection response; 21 (43\%) hospitals reported a regional group that did not meet regularly, but could mobilize quickly.

\section{DISCUSSION}

This needs assessment demonstrates the following points:
1. The US Ebola experience improved hospitals' familiarity with HICS and implementation of outbreak simulation and communication strategies.

2. $57 \%$ of respondents were familiar with HICS prior to the US Ebola experience.

3. Healthcare epidemiologists often serve as the Medical Technical Specialist during HICS activation for a serious emerging infection.

4. More than $90 \%$ of responding hospitals have treated suspected/confirmed cases of CRE; $>50 \%$ of hospitals have treated suspected/confirmed cases of vaccinepreventable diseases, pandemic influenza, and tuberculosis. Two-thirds of hospitals activated HICS due to 1 of these infections.

5. Most hospitals have trained public relations communication staff; $<50 \%$ of healthcare epidemiologists have received media training.

6. Three-quarters of hospitals report including support staff on emerging pathogens and serious infectious diseases training.

7. Ninety percent of responding hospitals utilize outbreak simulation, including simulation laboratories, but infrequently include ambulatory and medical/surgical ward staff.

8. Few hospitals provide guidance to postacute-care and LTCFs during an outbreak or epidemic. 